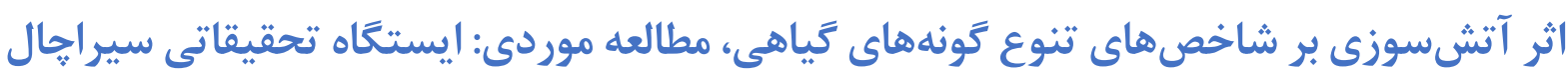

$$
\begin{aligned}
& \text { بهنام حمزهُ، مصطفى خوشنويس، يروانه عشورى، ولى اله مظفريان و هومن روانبخش }
\end{aligned}
$$

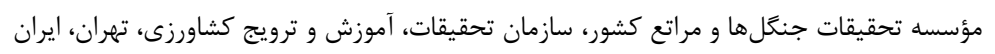

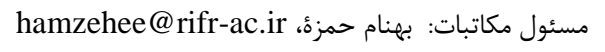

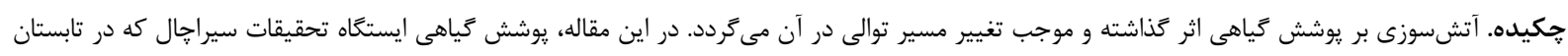

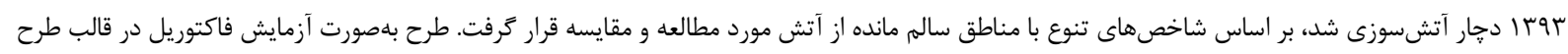

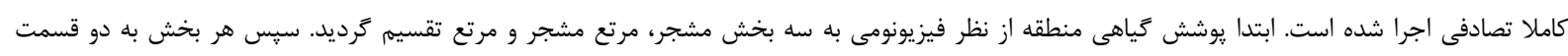

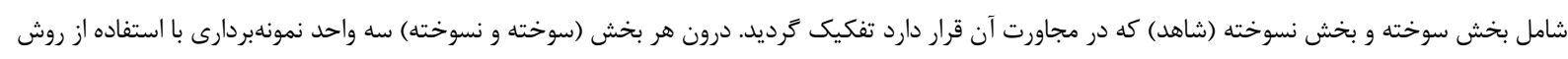

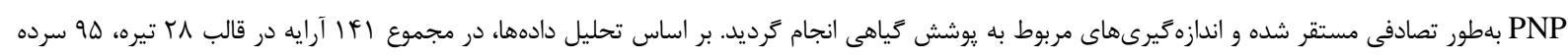

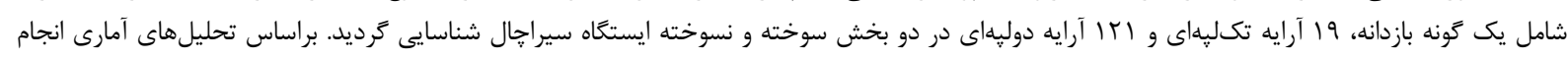

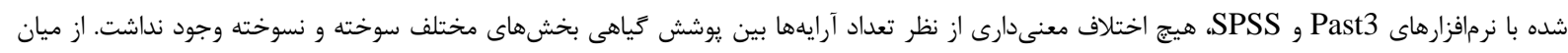

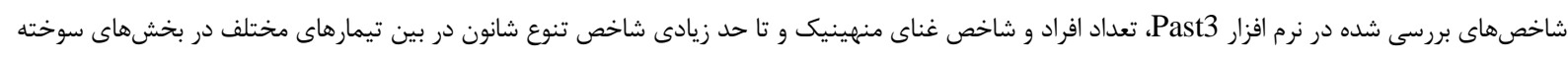

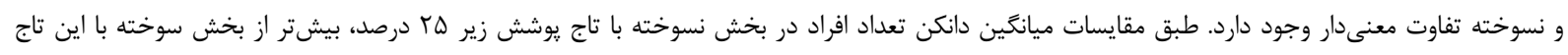

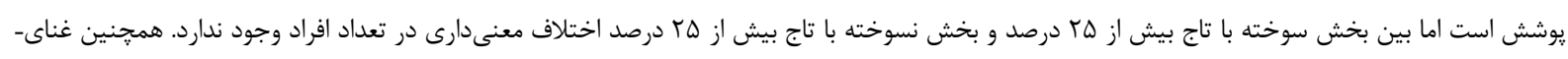

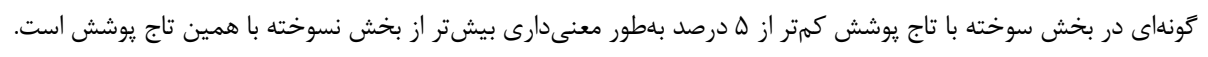

$$
\text { وازههاى كليدى. ارس، البرز مركزى، ايران، يوشش گياهى، توالى ثانويه }
$$

\title{
The effect of fire on vegetation diversity indices, a case study: Sirachal research station
}

\section{Behnam Hamzeh'ee, Mostafa Khoshnevis, Parvaneh Ashouri, Vailolah Mozaffarian \& Hooman Ravanbakhsh} Research Institute of Forests and Rangelands, Agricultural Research, Education and Extention Organization (AREEO), Tehran, Iran

Correspondent author: Behnam Hamzeh'ee, hamzehee@rifr-ac.ir

\begin{abstract}
Fire affects vegetation and changes plant succession. In this paper, the vegetation of Sirachal Research Station, which burned in the summer of 2014, was studied and compared with the unburnt areas, based on biodiversity indices. The research was implemented as a factorial experiment in a completely randomized design. First, on the basis of physiognomy, the area was divided into three parts: shrubland, shrubland-rangeland, and rangeland. Each part was, then, divided into two sections, including a burnt area and an adjacent unburnt area (control area). In each area (burnt and unburnt), three sampling units were randomly assigned using PNP method, and vegetation measurements were subsequently performed. Based on data analysis, a total of 141 taxa were identified, belonging to 28 families and 95 genera, including one species of Gymnosperm, 19 monocotyledons and 121 dicotyledons in two burnt and unburnt areas of Sirachal Station. Based on the statistical analysis, using Past 3 and SPSS softwares, there was no significant difference in the number of taxa between the vegetation of the burnt and unburnt areas. Of the indicators analyzed in Past3, the number of individual, the index of Menhinick's richness and the Shannon diversity index were significantly different in the treatments sampled from the burnt and unburnt areas. According to the Duncan test average, the number of individuals in the unburnt area, with a canopy cover below $25 \%$, was greater than that in the burnt area, with the same canopy cover, however, no significant difference was observed between the individuals in the burnt area and unburnt area, with the same canopy cover of more than $25 \%$. Also, the richness of the burnt area with a canopy of less than 5\% is significantly higher than that in the unburnt area with the same canopy cover.
\end{abstract}

Keywords. Central Alborz, Iran, Juniperus excelsa, secondary succession

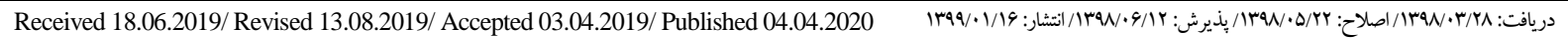


مى آيد، منطقه تختى ييلاق در قسمت جنوبى پارك ملى كلستان مطالعه شده است (Shokri et al., 2001). نتايج نشان داد كاد كه درصد يوشش تاجى و توده گياهى بالاى سطح خاك در منطقه

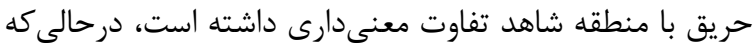

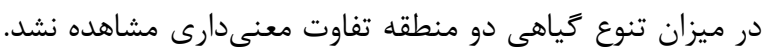
Aegilops همجنين در اين تحقيق مشخص شد كه كَندميانى مانند و Stipa pennata L. Avena wiestii Stued. ،tauschii Coss. Festuca valesiaca Schleich. ex Gaudin در مقايسه با منطقه مجاور خود، در سطح ا درصد افزايش معنىدارى

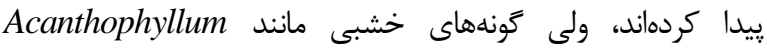
Onobrychis cornuta (L.) pungens (Bunge) Boiss. Rosa persica Michx. „ Cotoneaster ovatus Pojark. Desv. ex Juss.

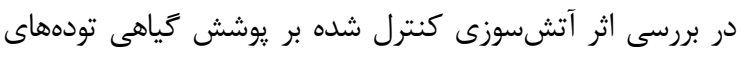
جوان Pinus pinaster مشخص شد كه يوشش علفى بيشترين ميزان رشد و توسعه را داشته است (Moreira et al., 2003).

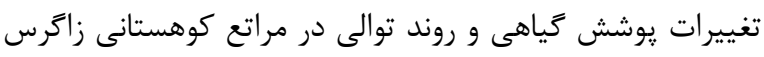
Fattahi \& ) تحت تاثير آتشسوزى مطالعه شده است

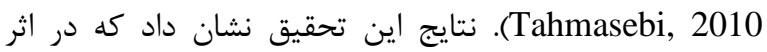

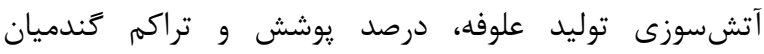

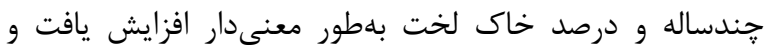

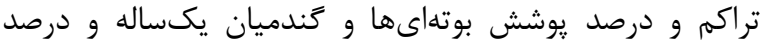
يوشش لاشبرى كاهش معنى دار داشت. تنوع گَونهاى نيز در دران

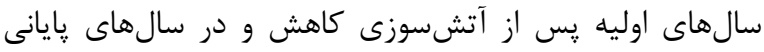

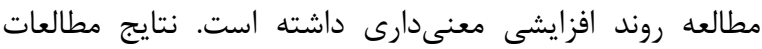

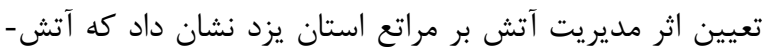

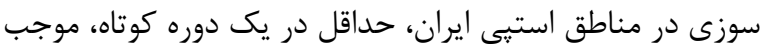

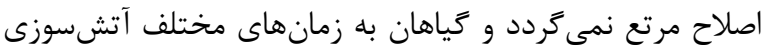

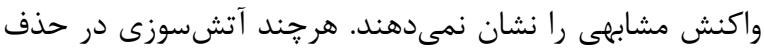

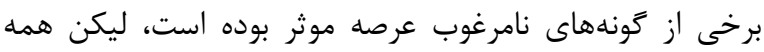

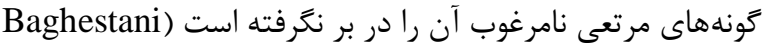
Maybodi et al., 2010 مرتع يير گلسرخ بهبهان نشان داد كه در منطقه آتشسوزى درصد يوشش تياهى كلاس III (كياهان با خوشخ خوراكى خيلى

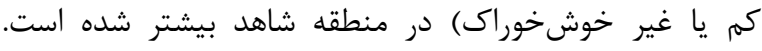
همجنين درصد يوشش كياهى منطقه آتشسوزى از نظر كميت

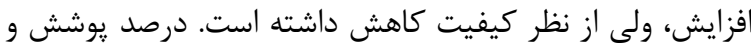

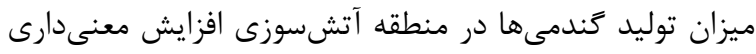
نسبت به منطقه شاهد نشان داد، در صورتى كه در منطقه شاهد درصد يوشش و ميزان توليد يهنبركان افزايش معنى دارى داشته
مقلمه

حياهان در طبيعت همواره در معرض آسيبها و تنشهاى

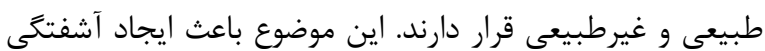

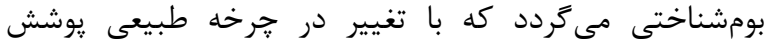

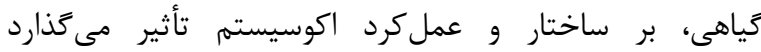

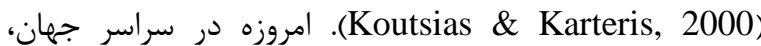

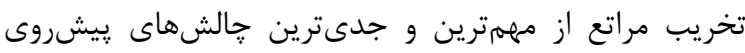
برنامههاى توسعه و مديريت منابع طبيعى است. آتشسوزى همانند يوشش كياهى مؤلفه طبيعى مرتع بلهمار

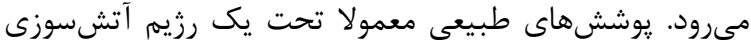

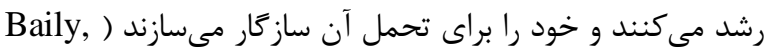

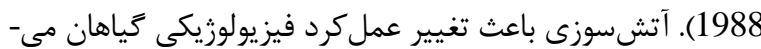

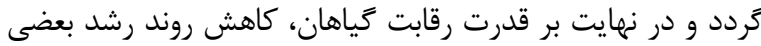
از كونهها و يا افزايش رشد كونههاى ديكر و مراحل توالى اثركذار

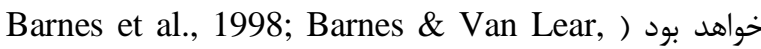

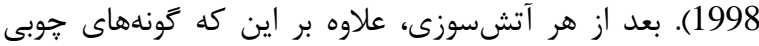

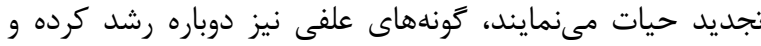

كياهان يكساله ظاهر مى كردند (Keeley \& Keeley, 1981) آتشسوزى بر خصوصيات فيزيكى و شيميايى خاك از جمله

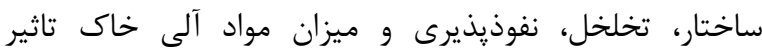

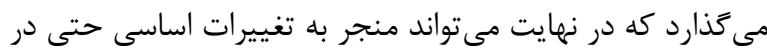
نوع يوشش كياهى گردد. در عرصهايى مانند ايستخاه تحقيقات

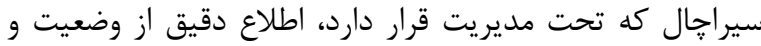

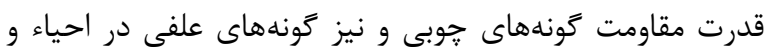
زادآورى مجدد، از لحاظ مديريتى بسيار مههم بوده و شايد بتواند

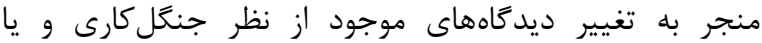

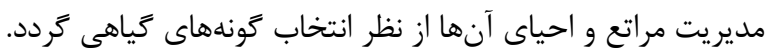

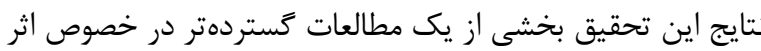
آتش بر يوشش كياهى و بانك بذر خاك است كه در اين مقاله به آنه اثر آتش بر يوشش كياهى و فلور منطقه يرداخته شده است.

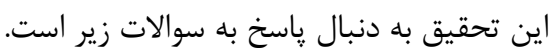

() آتشسوزى سبب جه تغييراتى در يوشش كياهى مناطق

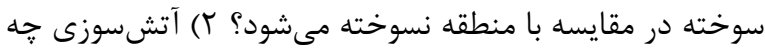

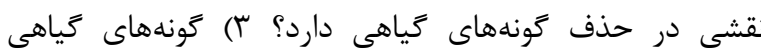

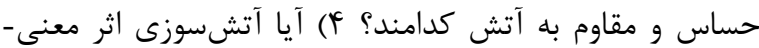
دارى بر تنوع گونههاى گياهى دارن؟ در ارتباط با اثر آتش بر يوشش كياهي، مطالعات متافي متعدد در

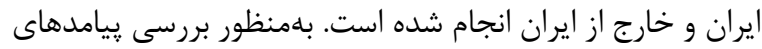

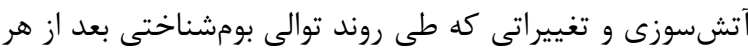

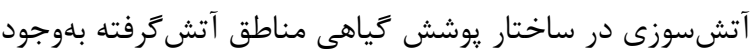


استان كرمانشاه نشان داد كه شاخصهاى تنوع سيميسون و شانون

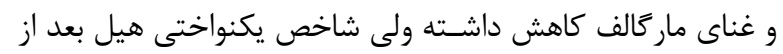

آتشسوزى افزايش داشته است (Talai Tabar et al., 2017).

\section{مواد و روشها}

منطقه مورد مطالعه

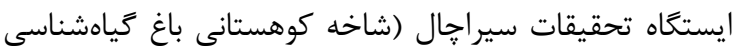

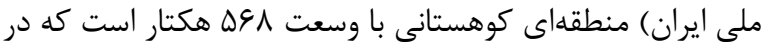

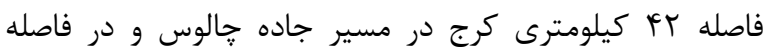

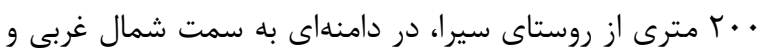

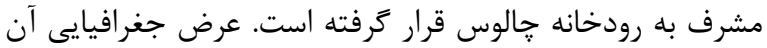

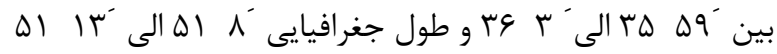
است. پايينترين نقطه ارتفاعى آن از سطح دريا، در كنار رودخانه

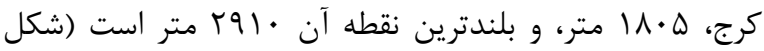
(1). در حومه آن دو روستاى رىزمين و مو سيرا قرار دارد.

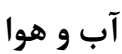

رزيم بارندكى سيراجال مانند اكثر نقاط ايران تحت تأثير مراكز

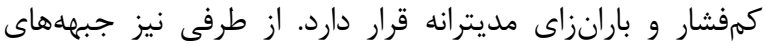

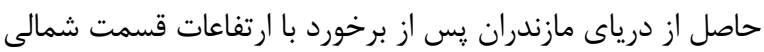
در صورت كافى بودن قدرت بارانزايى، توليد بارندگى مى كنند.

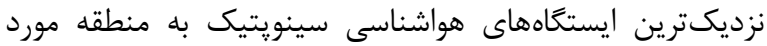

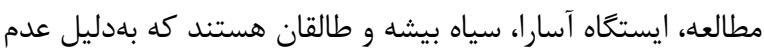
دسترسى به دادهاى ايستخاه آسارا، از دادهاى ايستخاه سياه بيشه

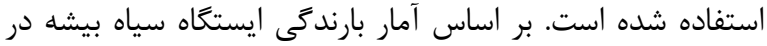

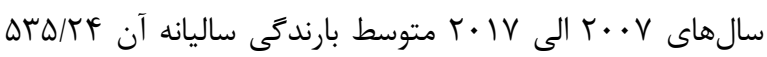
ميلى متر محاسبه شده است. حداقل و حداكثر بارندگى ساليانه در

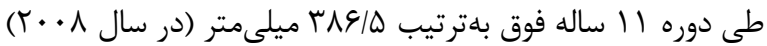

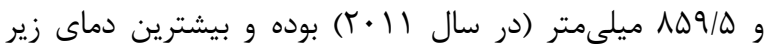
صفر در ماههاى دى، بهمن و اسفند بوده است. حداكثر مطلق

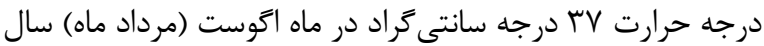

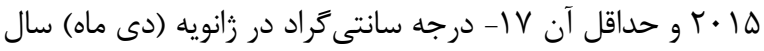

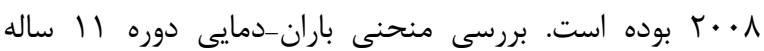

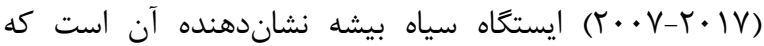

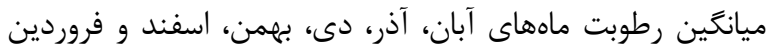

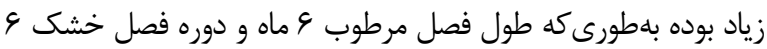
ماه است (شكل r). بيشترين ميانگين ميزان بارش در ماههاى بهمن

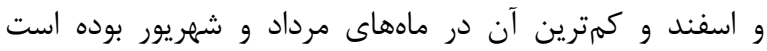

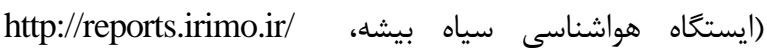
jasperserver/login.htm . اقليم منطقه طبق روش كوسن، استيى بئه
است (Javadi \& Mamoon, 2011). مطالعه ويزخى هاى يوشش كياهى بعد از آتشسوزى نشان داد كه در اثر آتشسوزى

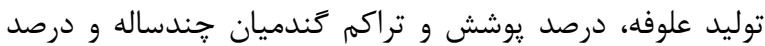

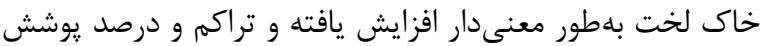

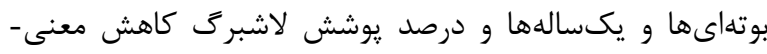

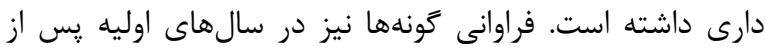
آتشسوزى كاهش و در سالهاى يايانى مطالعه روند افزايشى آنى

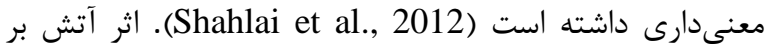
روى تنوع يوشش كياهى و نيز تنوع و تراكم بانك بذر خاك در

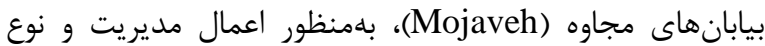
بذركارى بعد از آتشسوزى مورد مطالعه قرار كرفته است

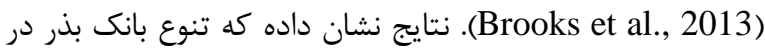
دو سال اول بعد از آتشسوزى كاهش يافته است. كاهش بانك

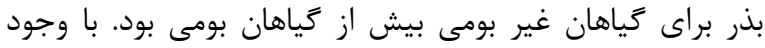

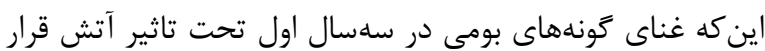

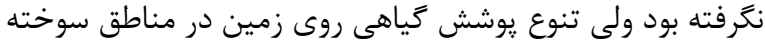

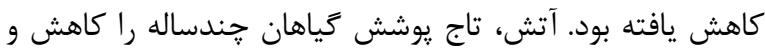

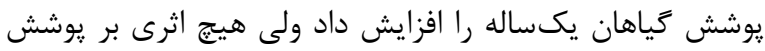

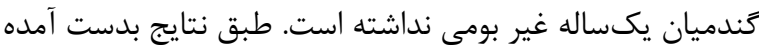
از اثر آتش بر تنوع گونههاى گياهى زاگرس (منطقه حفاظت شده

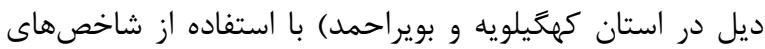

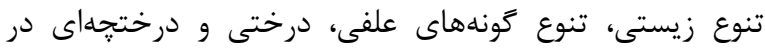

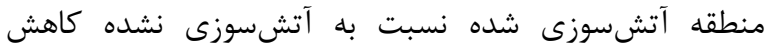
معنى دارى داشته است (Khalilpoor et al., 2013). همجنين اختلاف معنى دارى در غناى گَونهاى و تنوع گَونهاى ميان مناطق

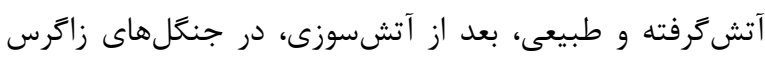

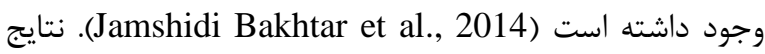
مطالعه تنوع كياهى پس از آتشسوزى در يك مرتع نيمه استبى

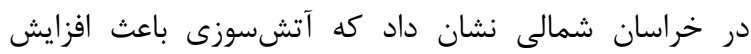
شاخصهاى تنوع، غنا و يكنواختى شد كه مقدار اين شاخص بان بان

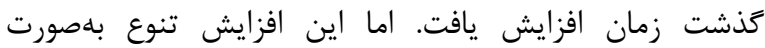

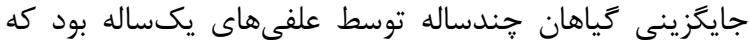
ممكن است سبب كاهش بايدارى اكوسيستم در برابر ناملايمات محيطى گردد (Rafiee et al., 2015). نتايج اثر آتش بر ساختار و و

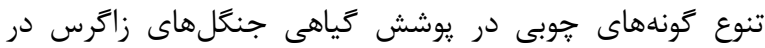

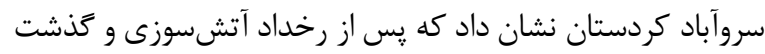

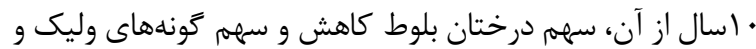
بادام افزايش و در تونه بنه تفاوتى وجود نداشته است ( Moradi et

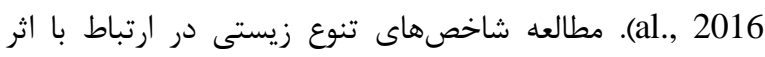
كوتاه مدت آتش بر يوشش كياهى و خاك در مراتع درود فرامان 


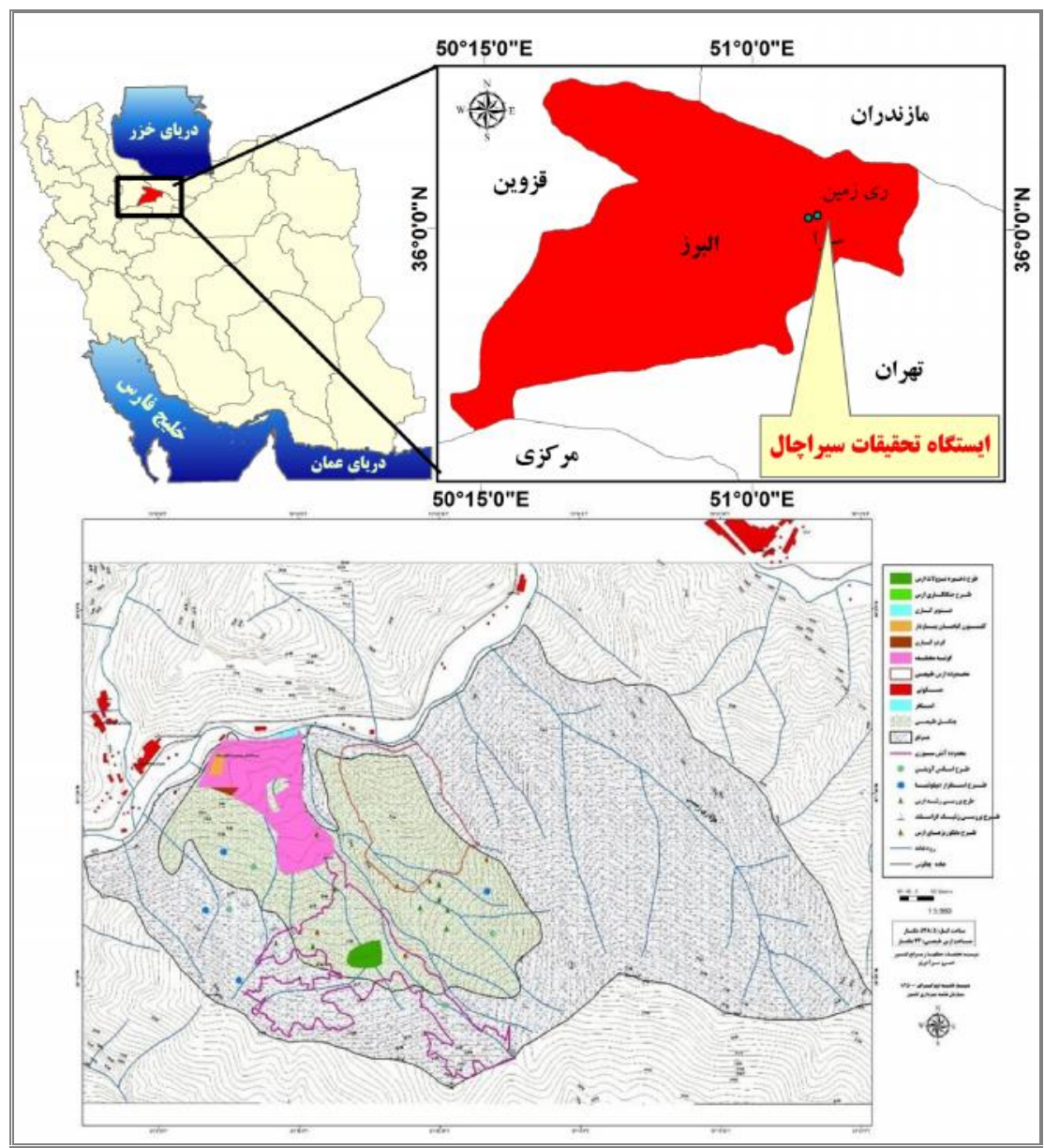

شكل ا- موقعيت جغرافيايى ايستكاه سيراجال (Hamzehee, 2019)

Fig. 1. Geographic location of the Sirachal Station (Hamzehee, 2019)

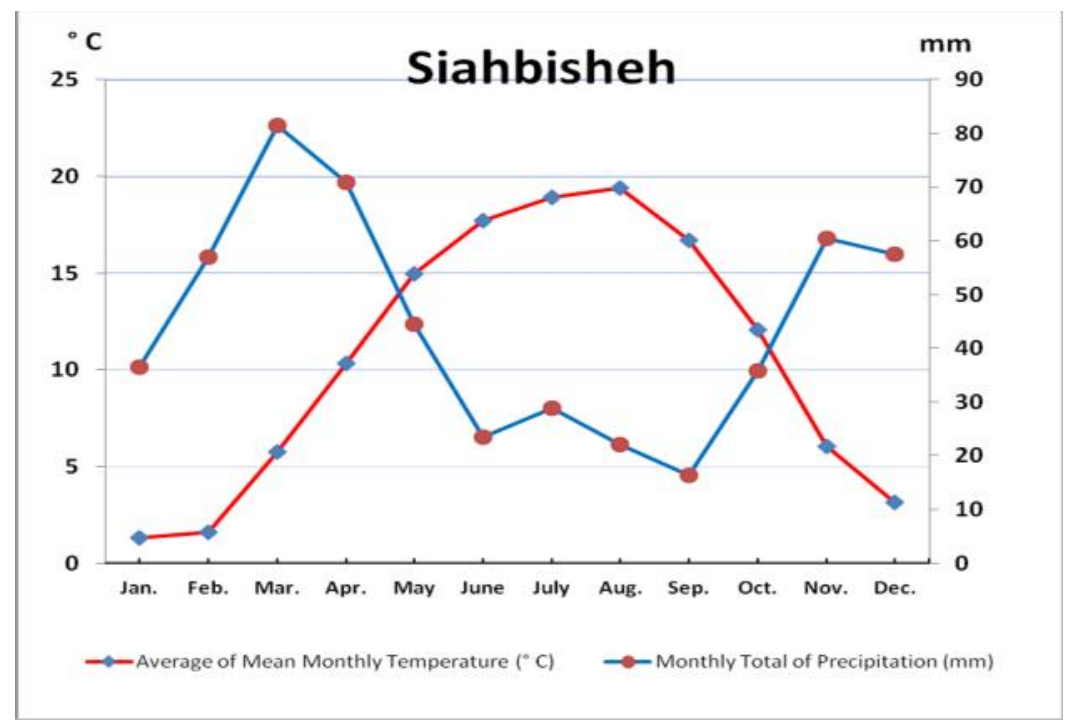

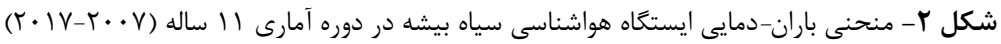

Fig. 2. Ombrothermic diagram of Siah Bisheh climatic station in an 11-year period (2007-2017). 
Fياهى بر اساس درصد تراكم درختان و درختجهها (بيشتر از ه T درصد، ه تا ها درصد و كمتر از ه درصد) به به سه بخش مش مشجر، مرتع مشجر و مرتع تقسيم شد. سيس هر منطقه به دو بخش سوخته و نسوخته (شاهد) در مجاورت آن، تفكيك گرديد. درون هر بخش سه واحد نمونهبردارى، با استفاده از روش PNP (Kalkhan et al., 2007)

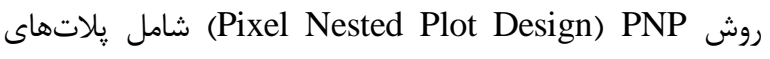

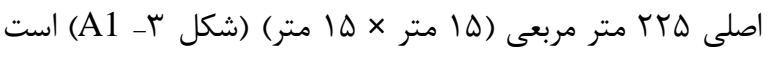

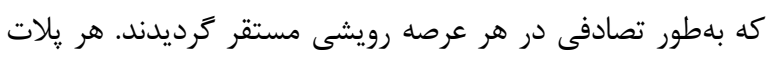

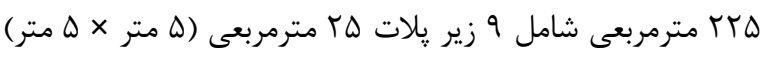

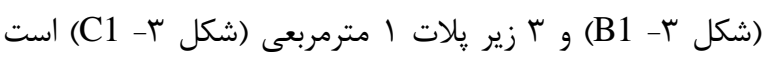

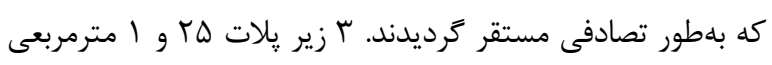
بلهطور تصادفى از ميان اعداد ا تا و مورد نمونهبردارى قرار كرفت.

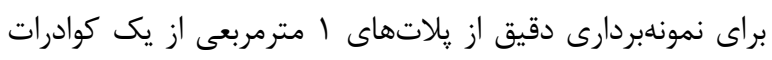

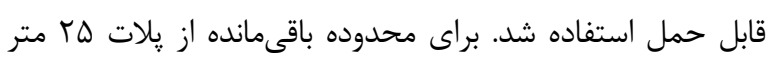

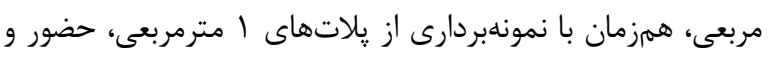

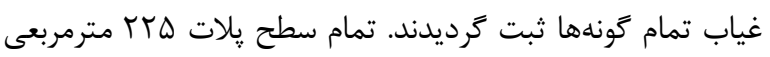

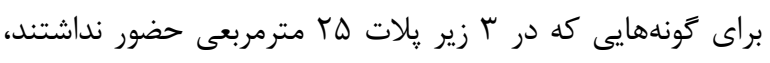

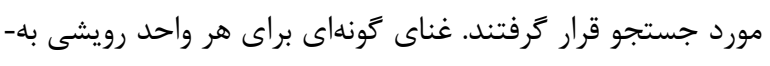
وسيله فهرست گونههايى كه از يّلاتهاى تكرارشده درون هر واحد

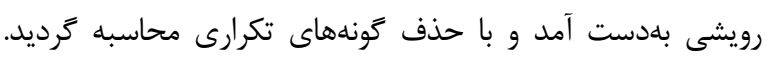

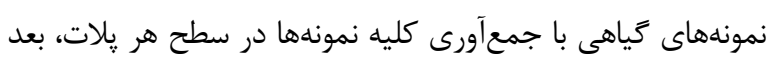

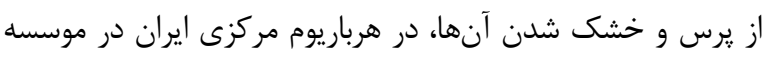

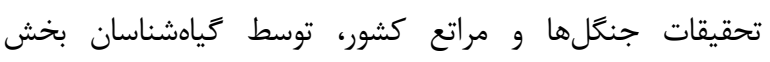

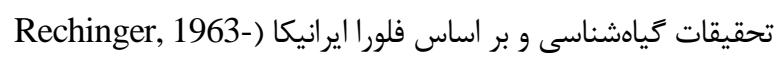

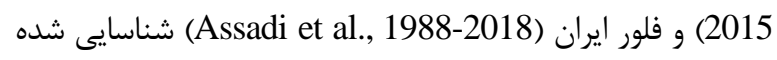
است و از طبقهبندى

تحليل دادهها

تحليل يوشش گياهى در دو بخش سوخته و نسوخته با استفاده

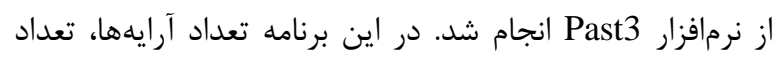

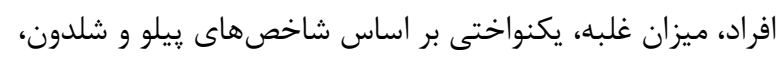

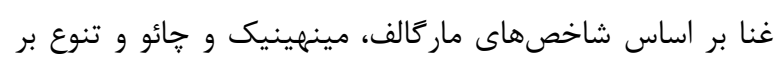
اساس شاخصهاى سيميسون، شانون و فيشر آلفا محاسبه ميى

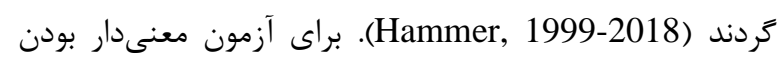
شاخصها، از برنامه آمارى SPSS و آناليز واريانس يك برطرفه به همراه مقايسات ميانگين دانكن استفاده گرديد.

\section{نتنايج}

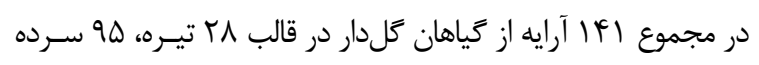

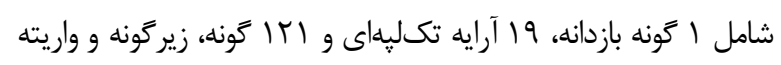

سرد بوده و در طبقهبندى آمبرزه در اقليم نيمهمرطوب قرار مى گيرد (Akbarzadeh, 1994). يوشش تياهى

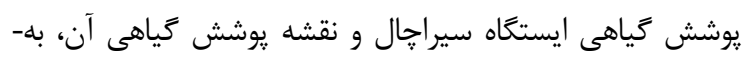

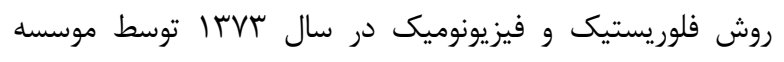

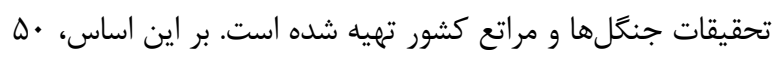

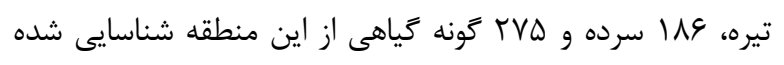

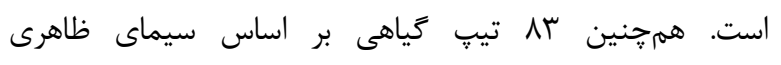
(فيزيونومى) و تركيب فلوريستيك آنها تشخيص داده شده است برين

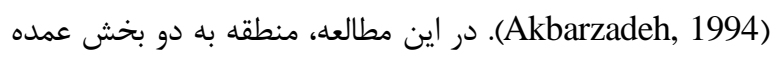
شامل جوامع طبيعى و نيمه طبيعى و بخش تخريب يافته تقسيم

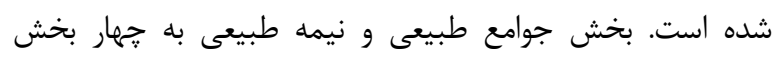

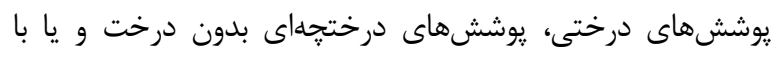

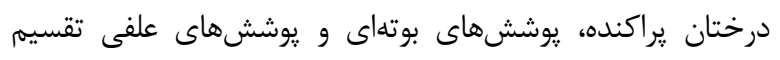

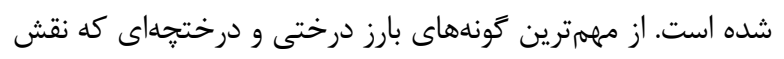
اصلى را در تشكيل تيیهاى خياهى منطقه دارند مىتوان از خونه\& C.A.Mey. Juniperus excelsa M.Bieb. هاى ،Ulmus minor Miller ،Cotoneaster nummularia Fisch Cerasus ‘B. integerrima Bunge. ‘Berberis vulgaris L. g Rosa iberica Stev. microcarpa (C.A.Mey.) Boiss. (1994) Akbarzadeh . نام برد Amygdalus lycioides Spach. گونههاى بوتهاى و علفى زير را كه در تشكيل تيبهاى گياهى بهـ عنوان گونه بارز مطرح هستند معرفى كرده است: Acantholimon sp., Acanthophyllum microcephalum Boiss., Agropyron tauri Boiss. \& Bal., A. trichophorum (Link) Richter., Alopecurus textilis Boiss., Astragalus brachycalyx Fischer., Bromus tomentellus Boiss., Buffonia macrocarpa Ser., Cephalaria microcephala Boiss., Coronilla varia L., Cousina sp., Dianthus orientalis Adams., Diplotaenia cachrydifolia Boiss., Ferula ovina (Boiss.) Boiss., Galium aparine L., Helichrysum oligocephalum DC., Hippomaranthum crispum (Bieb.) Fedtsch., Hypericum scabrum L., Psathyrostachys fragilis (Boiss.) Nevski, Leucopoa sclerophylla (Boiss. \& Hohen.) V. Krecz \& Drobov., Rumex scutatus L., Thalictrum sp., Thymus kotschyanus Boiss. \& Hohen.

\section{روش يزوهش}

دو عامل وضعيت آشفتگى (بخش سوخته و بخش نسوخته) و

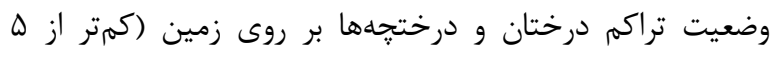

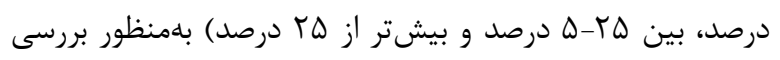

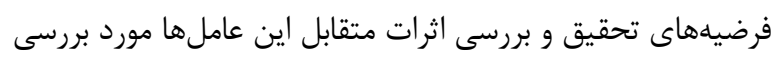

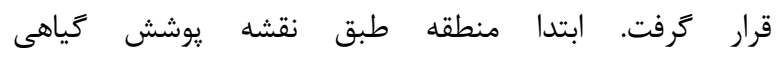
و و با توجه به سيماى ظاهرى : يوشش (Akbarzadeh, 1994) 
A

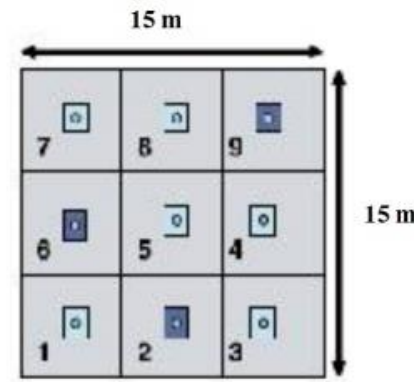

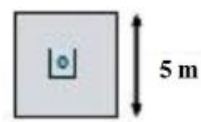

C $\quad 1 \mathrm{~m}^{2}$
D

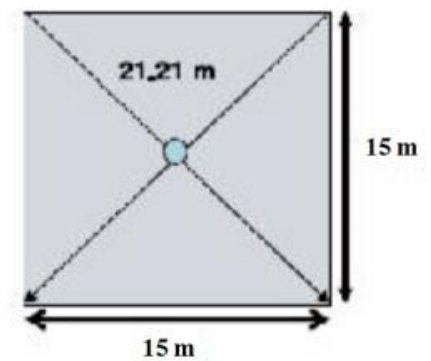

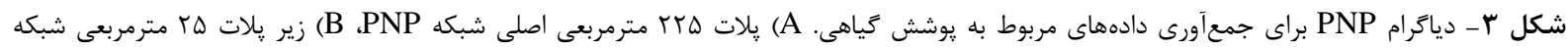

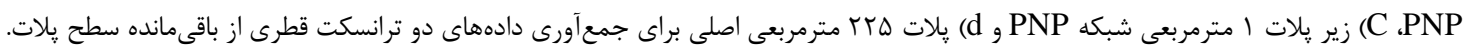

Fig. 3. PNP diagram for collecting vegetation data. A) main plot of PNP network with $225 \mathrm{~m}^{2}$ area; B) subplot of PNP network with $25 \mathrm{~m}^{2}$ area; C) subplot of PNP network with $1 \mathrm{~m}^{2}$ area; and d) a main plot of $225 \mathrm{~m}^{2}$ for collecting two transect data of the remaining surface of the plot.

يك گونه هستند. بزرگترين سردهها در دو بخش سوخته و نسـوخته

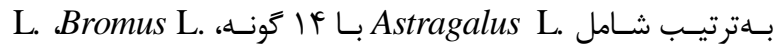

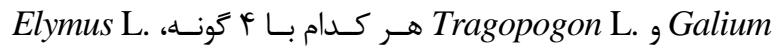

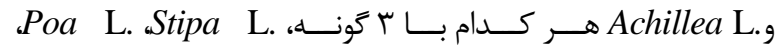
L. “Centaurea L. ‘Ferula L. “Onobrychis Adans. Thlaspi Aethionema R.Br. ،Tanacetum L. Senecio L. Arenaria L. ،Cotoneasetr Medik. ،Tulipa L. ‘L. Hypericum L. Euphorbia L. Silene L. Dianthus

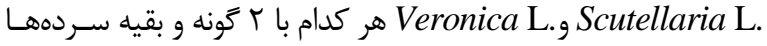
تك گونهاى هستند (جدول ()). براسـاس تحليـلهـاى آمـارى انجـام شده (جدول r) هيج اختلاف معنى دارى از نظر تعداد آرايـههـا بـين بخشهاى مختلف سوخته و نسوخته وجود نداشته است.

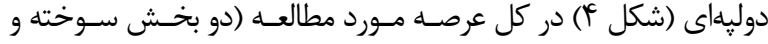

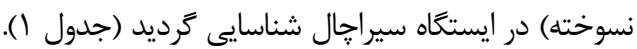

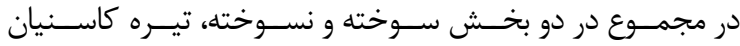

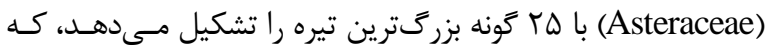

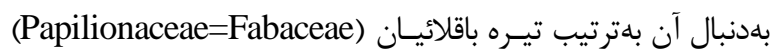

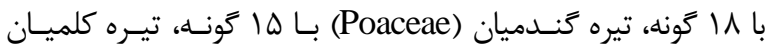
(Brassicaceae)

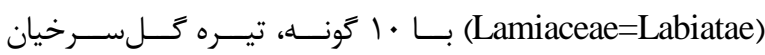
(Caryophyllaceae) بـا م عونــه، تيـره ميخكيـان (Rosaceae)

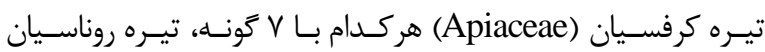
(Rubiaceae) ميمونيان (Scrophulariaceae) هركدام با ץ گ گونسه و تيـره خواجـهـ

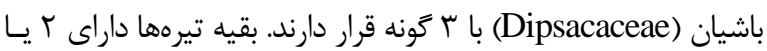

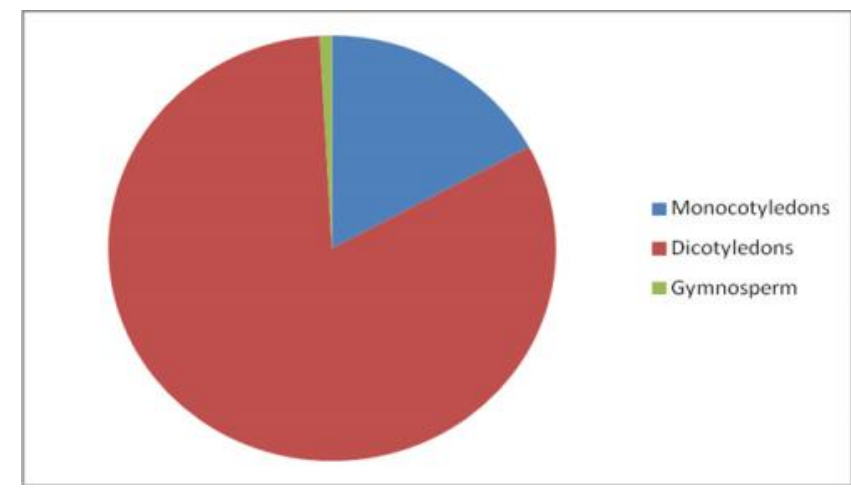

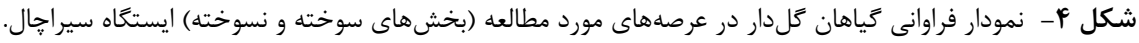

Fig. 4. Frequency chart of flowering plants in the burnt and unburnt areas of Sirachal Station. 
كلميان با 9/9 درصد و تيره نعنائيان با V/I درصد بودند. بر اساس نتايج ANOVA، از ميان شاخصهاى بررسى شده در نرم

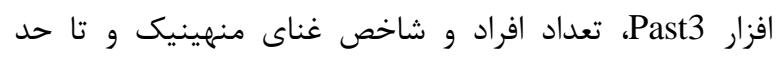
زيادى شاخص تنوع شانون (با توجه به نتايج مقايسات ميانخين) در بين تيمارهاى مختلف (4 گروه) در بخشهاى سوخته و

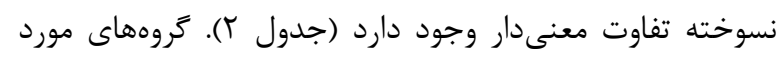

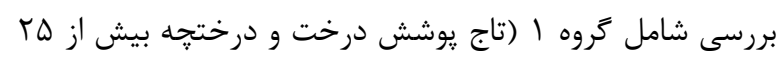

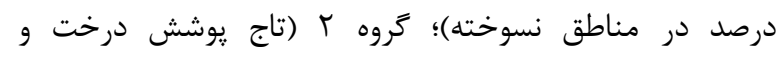

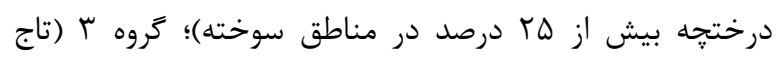

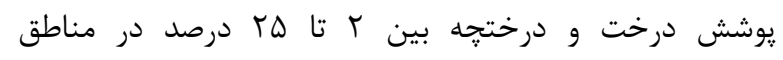

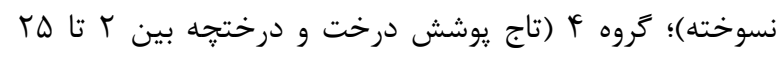

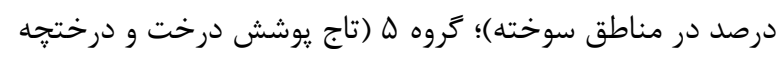

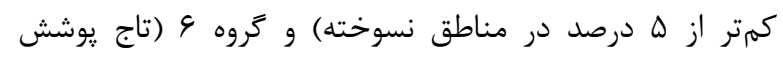
درخت و درختجه كممتر از له درصد در مناطق سوخته) هستند.

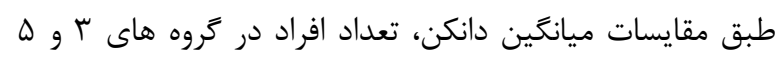
بهطور معنى دارى بيشتر از زروه هاى أ و و است. بهعبارت ديق ديخر

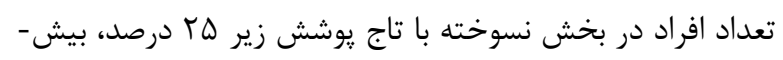

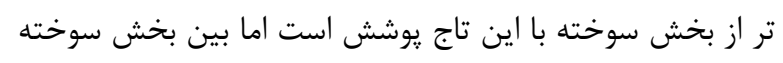

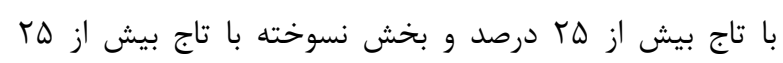

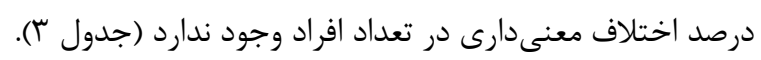

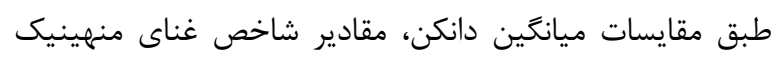

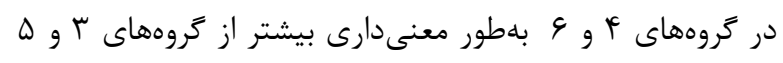

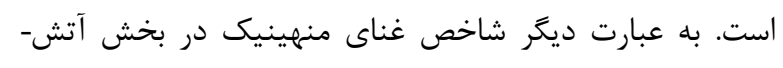

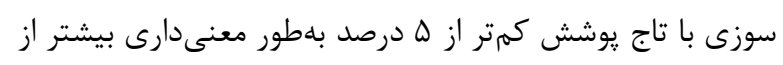

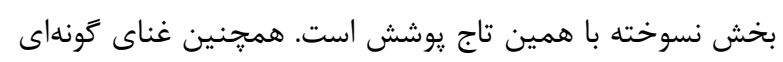

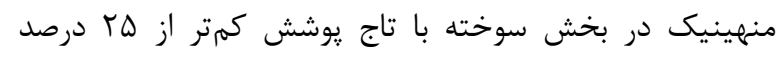

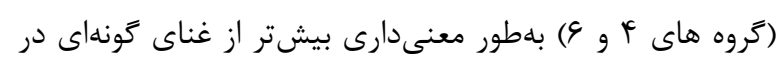

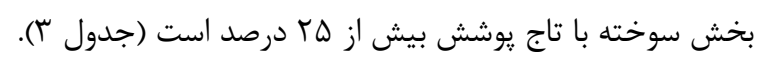

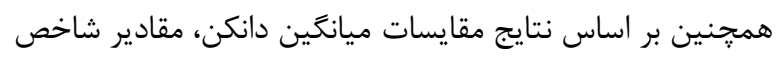

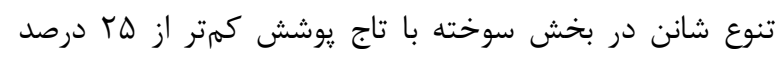

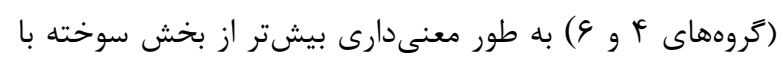

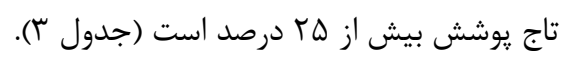

\section{بحث و نتبجه تيرى}

بسيارى از آشفتگىها مانند آتش، كه از ديرباز در اكوسيستمها بروز يافتهاند، از اجزاء طبيعى جرخه حيات بوده كه نتيجه آن تطابق آنقان

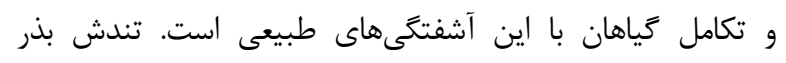
بسيارى از ₹ياهان تحت تاثير نوسانات دما قرار داشته و نقش آتش و

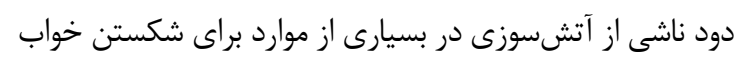

در كل بخش نسوخته V|1 آرايه و در كل بخش سوخته 111 آ

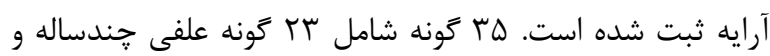

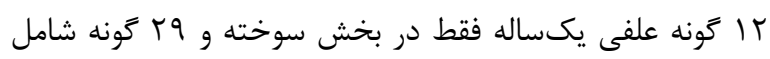

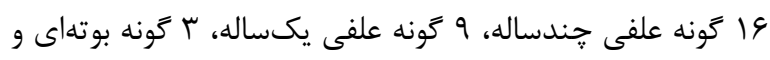
يك زونه درختجهاى فقط در بخش نسوخته حضور داشته (جدول (1) و بقيه گونهها در هر دو بخش مشترك بون بودهاند. در

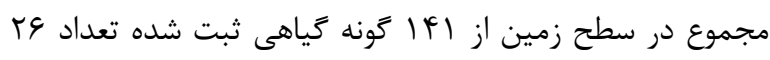

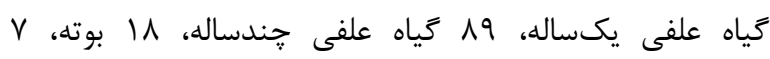

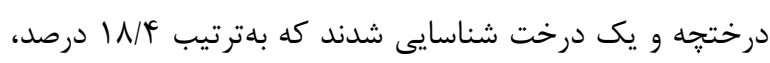

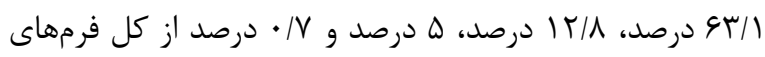
رويشى را بهخود اختصاص دادند. تيرههاى با ب و تعداد بالاتر

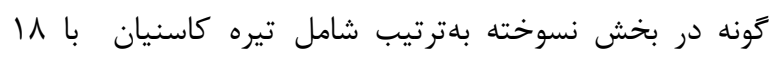

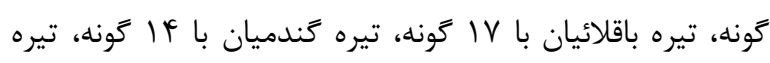

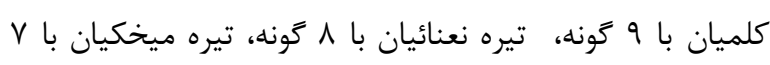

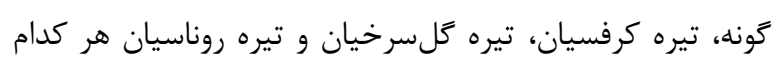

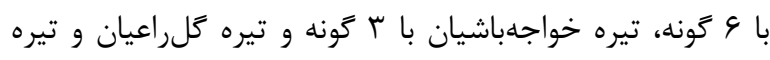

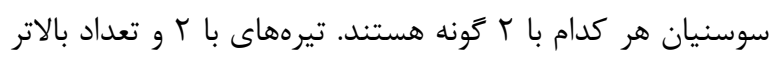

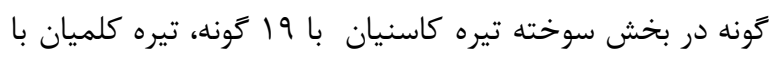

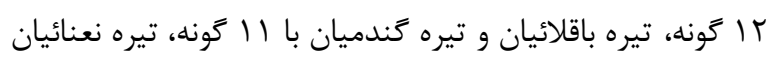

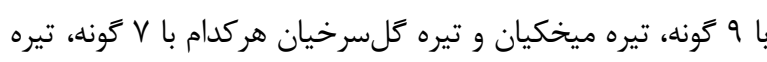

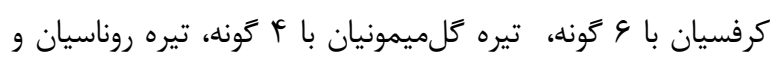
تيره سوسنيان با ب گ گونه، تيره كاوزبانيان (Boraginaceae)، تيره فرفيونيان (Euphorbiaceae)، تيره كل (راعيان و تيره خواجه باشيان

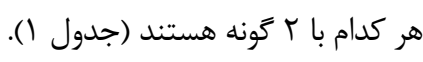

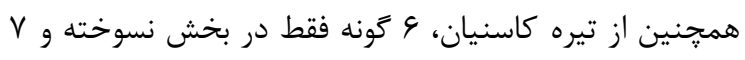

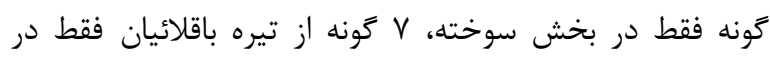

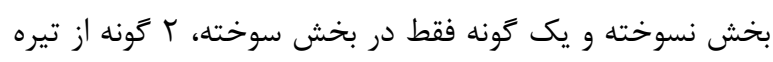
كلميان فقط در بخش نسوخته و 4 گونه فقط در بخش سوخت سوخته،

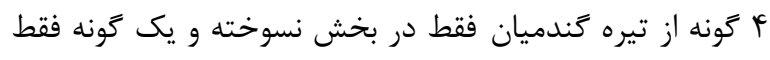

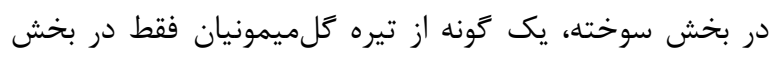

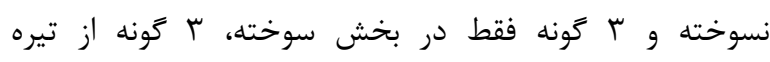

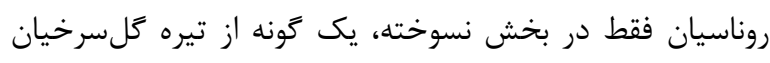

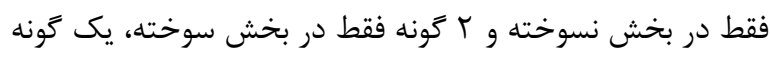

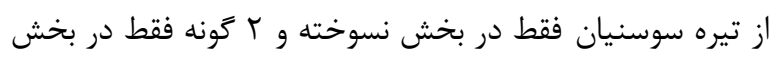

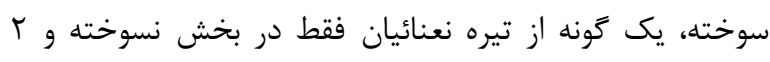

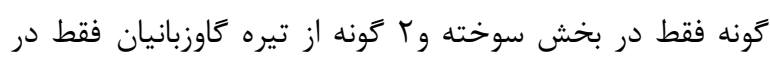
بخش سوخته حضور داشتهاند (جدول (1). مههمترين تيرهها از نظر

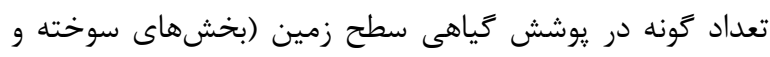

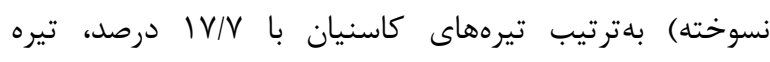

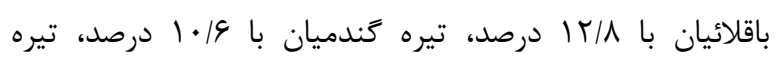




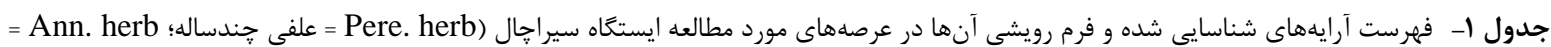

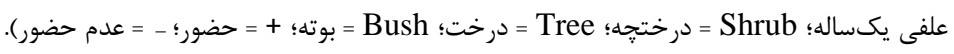

Table 1. The list of identified taxa and their life forms in the studied areas of Sirachal Station (Pere. herb $=$ Perennial herb, Ann. herb = Annual herb, $+=$ presence, $-=$ absence) .

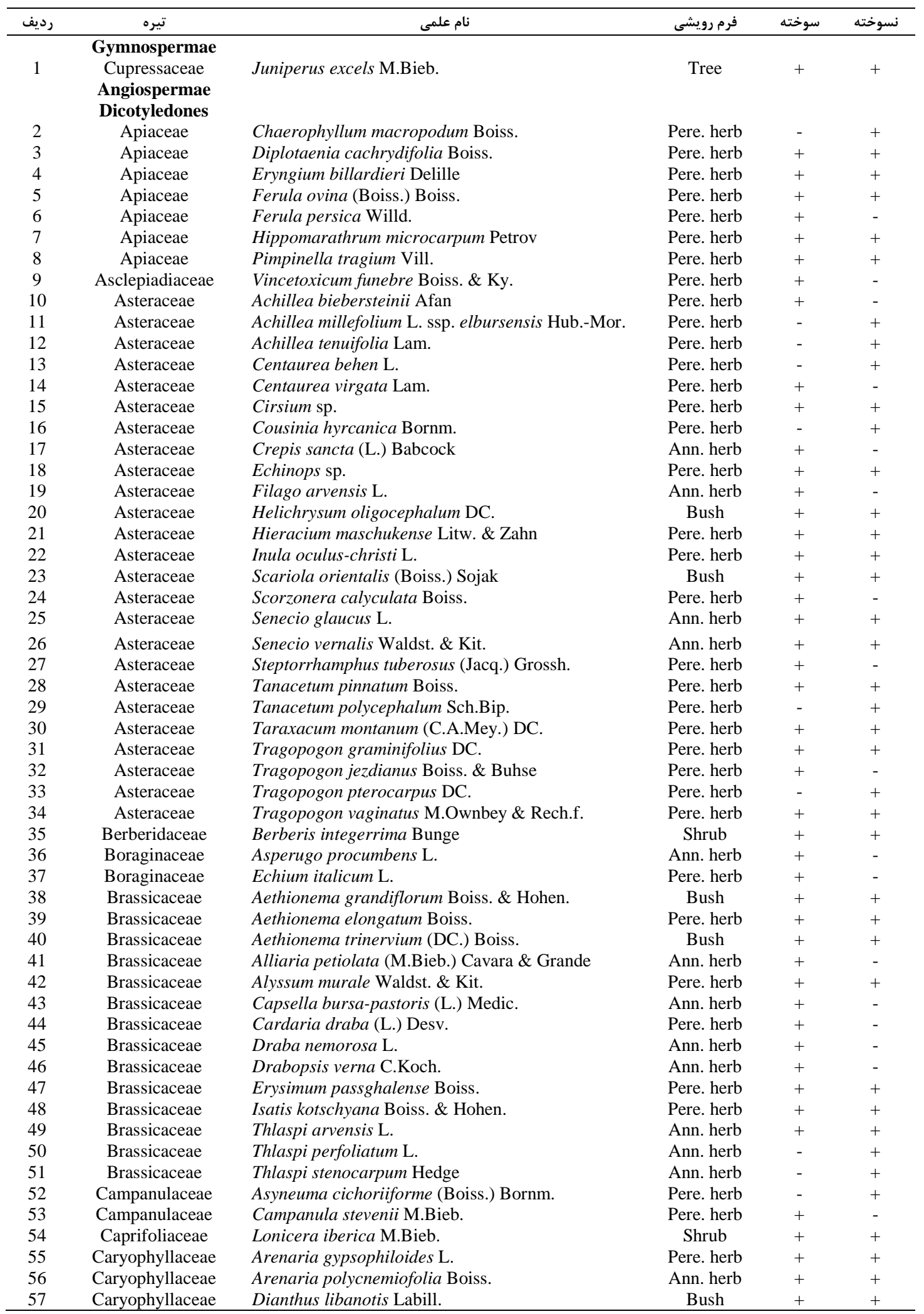




\begin{tabular}{|c|c|c|c|c|c|}
\hline 58 & Caryophyllaceae & Dianthus orientalis Adams & Bush & + & + \\
\hline 59 & Caryophyllaceae & Mesostemma kotschyana (Fenzl) Vved. & Pere. herb & + & + \\
\hline 60 & Caryophyllaceae & Silene aucheriana Boiss. & Bush & + & + \\
\hline 61 & Caryophyllaceae & Silene marshalii C.A.Mey. & Bush & + & + \\
\hline 62 & Dipsacaceae & Cephalaria microcephala Boiss. & Pere. herb & + & + \\
\hline 63 & Dipsacaceae & Pterocehalus canus Coult. ex DC. & Pere. Herb & + & + \\
\hline 64 & Dipsacaceae & Scabiosa sp. & Ann. herb & - & + \\
\hline 65 & Euphorbiaceae & Euphorbia cheiradenia Boiss. \& Hohen. ex Boiss. & Pere. herb & + & + \\
\hline 66 & Euphorbiaceae & Euphorbia sp. & Pere. herb & + & - \\
\hline 67 & Fumariaceae & Fumaria veillantii Loisel. & Ann. herb & + & - \\
\hline 68 & Geraniaceae & Geranium tuberosum $\mathrm{L}$. & Pere. herb & + & + \\
\hline 69 & Hypericaceae & Hypericum scabrum L. & Bush & + & + \\
\hline 70 & Hypericaceae & Hypericum vermiculare Boiss. \& Hausskn. & Pere. herb & + & + \\
\hline 71 & Labiatae & Ajuga chamaecistus Ging. & Bush & + & + \\
\hline 72 & Labiatae & Lallemantia iberica (M.Bieb.) Fisch. \& C.A.Mey. & Ann. herb & - & + \\
\hline 73 & Labiatae & Marrubium astracanicum Jacq. & Pere. herb & + & - \\
\hline 74 & Labiatae & Phlomis olivieri Benth. & Pere. herb & + & + \\
\hline 75 & Labiatae & Scutellaria fragillima Rech.f. & Pere. herb & + & - \\
\hline 76 & Labiatae & Scutellaria pinnatifida A.Hamilt. & Bush & + & + \\
\hline 77 & Labiatae & Stachys lavandulifolia Vahl & Pere. herb & + & + \\
\hline 78 & Labiatae & Teucrium polium $\mathrm{L}$. & Pere. herb & + & + \\
\hline 79 & Labiatae & Thymus kotschyanus Boiss. \& Hohen. & Bush & + & + \\
\hline 80 & Labiatae & Ziziphora capitata $\mathrm{L}$. & Ann. herb & + & + \\
\hline 81 & Malvaceae & Malva neglecta Wallr. & Pere. herb & + & - \\
\hline 82 & Papilionaceae & Astragalus aegobromus Boiss. \& Hohen. & Pere. herb & + & + \\
\hline 83 & Papilionaceae & Astragalus caspicus M.Bieb. & Pere. herb & - & + \\
\hline 84 & Papilionaceae & Astragalus chrysostachys Boiss. & Bush & - & + \\
\hline 85 & Papilionaceae & Astragalus citrinus Bunge & Pere. herb & - & + \\
\hline 86 & Papilionaceae & Astragalus compactus Lam. & Bush & + & + \\
\hline 87 & Papilionaceae & Astragalus curvirostris Boiss. & Pere. herb & + & + \\
\hline 88 & Papilionaceae & Astragalus glumaceus Boiss. & Pere. herb & - & + \\
\hline 89 & Papilionaceae & Astragalus iranicus Bunge & Pere. herb & - & + \\
\hline 90 & Papilionaceae & Astragalus mesoleios Boiss. \& Hohen. & Pere. herb & - & + \\
\hline 91 & Papilionaceae & Astragalus pauxillis Maassoumi \& F.Ghahrem. & Pere. herb & + & + \\
\hline 92 & Papilionaceae & Astragalus pinetorum Boiss. & Pere. herb & + & + \\
\hline 93 & Papilionaceae & Astragalus podocarpus C.A.Mey. & Bush & + & + \\
\hline 94 & Papilionaceae & Astragalus rubrostriatus Bunge & Bush & + & + \\
\hline 95 & Papilionaceae & Astragalus submitis Boiss. \& Hohen. & Pere. herb & + & + \\
\hline 96 & Papilionaceae & Coronilla varia $\mathrm{L}$. & Pere. herb & + & + \\
\hline 97 & Papilionaceae & Medicago sativa $\mathrm{L}$. & Pere. herb & + & + \\
\hline 98 & Papilionaceae & Onobrychis cornuta (L.) Desv. & Bush & - & + \\
\hline 99 & Papilionaceae & Onobrychis sp. & Pere. herb & + & - \\
\hline 100 & Plumbaginaceae & Acantholimon festucaceum (Jaub. \& Spach) Boiss. & Bush & - & + \\
\hline 101 & Polygonaceae & Polygonum polycnemoides Jaub. \& Spach & Ann. herb & + & - \\
\hline 102 & Ranunculaceae & Adonis microcarpa DC. & Ann. herb & + & - \\
\hline 103 & Rosaceae & Alchemilla sp. & Pere. herb & + & - \\
\hline 104 & Rosaceae & Cerasus microcarpa (C.A.Mey.) Boiss. & Shrub & + & + \\
\hline 105 & Rosaceae & Cotoneaster nummularioides Pojark. & Shrub & + & + \\
\hline 106 & Rosaceae & Cotoneaster nummularius Fisch. \& C.A.Mey. & Shrub & + & + \\
\hline 107 & Rosaceae & Crataegus sp. & Shrub & - & + \\
\hline 108 & Rosaceae & Geum kokanicum Regel \& Schmahl. & Pere. herb & + & - \\
\hline 109 & Rosaceae & Potentilla recta $\mathrm{L}$. & Pere. herb & + & + \\
\hline 110 & Rosaceae & Rosa canina $\mathrm{L}$. & Shrub & + & + \\
\hline 111 & Rubiaceae & Asperula setosa Jaub. \& Spach & Ann. herb & - & + \\
\hline 112 & Rubiaceae & Crucianella chlorostachys Fisch. \& C.A.Mey. & Ann. herb & - & + \\
\hline 113 & Rubiaceae & Galium humifusum M.Bieb. & Pere. herb & + & + \\
\hline 114 & Rubiaceae & Galium hyrcanicum C.A.Mey. & Pere. herb & + & + \\
\hline 115 & Rubiaceae & Galium setaceum Lam. & Ann. herb & - & + \\
\hline 116 & Rubiaceae & Galium verum $\mathrm{L}$. & Pere. herb & + & + \\
\hline 117 & Santalaceae & Thesium kotschyanum Boiss. & Pere. herb & + & - \\
\hline 118 & Scrophulariaceae & Linaria lineolata Boiss. & Pere. herb & + & - \\
\hline 119 & Scrophulariaceae & Verbascum aucheri Hub.-Mor. & Pere. herb & + & + \\
\hline 120 & Scrophulariaceae & Veronica biloba Schreb. & Ann. herb & + & - \\
\hline 121 & Scrophulariaceae & Veronica orientalis Mill. & Pere. herb & + & - \\
\hline \multirow[t]{2}{*}{122} & Valerianaceae & Valeriana sisymbriifolia Vahl & Pere. herb & + & + \\
\hline & Monocotyledones & & & & \\
\hline 123 & Liliaceae & Allium scabriscapum Boiss. \& Ky. & Pere. herb & + & + \\
\hline 124 & Liliaceae & Gagea sp. & Pere. herb & + & - \\
\hline 125 & Liliaceae & Tulipa biebersteiniana Schults \& Schults f. & Pere. herb & + & - \\
\hline
\end{tabular}




\begin{tabular}{|c|c|c|c|c|c|}
\hline 126 & Liliaceae & Tulipa montana Lindl. & Pere. herb & - & + \\
\hline 127 & Poaceae & Boissiera squarrosa (Sol.) Nevski & Ann. herb & - & + \\
\hline 128 & Poaceae & Bromus danthoniae Trin. & Ann. herb & - & + \\
\hline 129 & Poaceae & Bromus tectorum $\mathrm{L}$. & Ann. herb & + & + \\
\hline 130 & Poaceae & Bromus tomentellus Boiss. & Pere. herb & + & + \\
\hline 131 & Poaceae & Bromus tomentosus Trin. & Pere. herb & + & + \\
\hline 132 & Poaceae & Dactylis glomerata L. & Pere. herb & + & + \\
\hline 133 & Poaceae & $\begin{array}{l}\text { Elymus hispidus (Opiz) Melderis var. podoperae } \\
\text { (Nab.) Assadi }\end{array}$ & Pere. herb & + & + \\
\hline 134 & Poaceae & $\begin{array}{l}\text { Elymus hispidus (Opiz) Melderis var. villosus } \\
\text { (Hackel) Assadi }\end{array}$ & Pere. herb & + & - \\
\hline 135 & Poaceae & Elymus libanoticus (Hackel) Melderis & Pere. herb & + & + \\
\hline 136 & Poaceae & $\begin{array}{l}\text { Leucopoa sclerophylla (Boiss. \& hohen.) V. Krecz. } \\
\text { \& Bobrov }\end{array}$ & Pere. herb & + & + \\
\hline 137 & Poaceae & Melica persica Kunth & Pere. herb & + & + \\
\hline 138 & Poaceae & Poa araratica Trautv. & Pere. herb & + & + \\
\hline 139 & Poaceae & Poa bulbosa L. & Pere. Herb & + & + \\
\hline 140 & Poaceae & Stipa arabica Trin. \& Rupr. var. arabica & Pere. herb & - & + \\
\hline 141 & Poaceae & Stipa lessingiana Trin. \& Rupr. & Pere. herb & - & + \\
\hline
\end{tabular}

$$
\text { جدول r- آناليز واريانس يكطرفه بين بخشهاى سوخته و نسوخته ايستگاه سيراجال. }
$$

Table 2. One-way analysis of variance between the burnt and unburnt areas of the Sirachal Station.

\begin{tabular}{|c|c|c|c|c|c|c|}
\hline معنادارى & $\mathrm{F}$ & ميانخين مربعات & مجموع مربعات & درجه آزادى & منبع تغييرات & شاخص تنوع زيستى \\
\hline \multirow[t]{3}{*}{. } & $1 / \cdot \Delta \Delta$ & $r 8 / \cdot 19$ & $11 \cdot / F F F$ & $\Delta$ & بين \& كروه & \\
\hline & & TY/TYT & $41.198 \mathrm{~V}$ & IT & درون گروهى & Taxa_S \\
\hline & & & $091 / 111$ & IV & كل & \\
\hline \multirow[t]{3}{*}{$\cdot|\cdot r|^{*}$} & $r / \cdot \wedge \Lambda$ & MIDF/VGV & Q.VVr/Arr & $\Delta$ & بين 9 كروه & \\
\hline & & FFF. IVTr & $\Delta T Y \wedge \Lambda / G G V$ & ir & درون گروهى & Individuals \\
\hline & & & $\mid F F \cdot G T / D$ & IV & كل & \\
\hline \multirow[t]{3}{*}{$\cdot / r \Delta F$} & I/DTE &.$/ \cdots r$ & $.1 \cdot 99$ & $\Delta$ & بين \& كروه & \\
\hline & & $.1 \cdot .1$ &.$/ .1 f$ & IT & درون گروهى & Dominance \\
\hline & & & $.1 \cdot r r$ & IV & كل & \\
\hline \multirow[t]{3}{*}{$\cdot / T \Delta F$} & 1/DTE &.$/ \cdot r$ & .1 .99 & $\Delta$ & بين 4 كروه & \\
\hline & & $\cdot 1 \cdot \cdot 1$ & $.1 \cdot 1 \mathrm{f}$ & IT & درون گروهى & Simpson \\
\hline & & & ש & IV & كل & \\
\hline \multirow[t]{3}{*}{$\cdot 1 \cdot V \Delta$} & r/9へV & $\cdot / 1 \Delta \Delta$ & $\cdot / V V r$ & $\Delta$ & بين \& كروه & \\
\hline & & $\cdot / \cdot \Delta \Lambda$ & .199 & IT & درون گروهى & Shannon \\
\hline & & & $1 / 4 \& 4$ & IV & كل & \\
\hline \multirow[t]{3}{*}{.$/ 19 V$} & $1 / 9 \cdot V$ &.$/ . r \Delta$ & . & $\Delta$ & بين 9 كروه & \\
\hline & &.$/ .14$ & $\cdot / 1 \Delta \Delta$ & IT & درون گروهى & Evenness \\
\hline & & &.$/ 4 V A$ & IV & كل & \\
\hline \multirow[t]{3}{*}{.$/ 14 q$} & $r / \cdot I r$ & $\cdot / \cdot 11$ & $\cdot / \mu \cdot \Delta$ & $\Delta$ & بين 4 كروه & \\
\hline & & $.1 \cdot f$ & . IANt & ir & درون گروهى & Brillouin \\
\hline & & & - /ANV & IV & كل & \\
\hline \multirow[t]{3}{*}{ (I.rr" } & $r / 091$ & $.19 V T$ & D & $\Delta$ & بين \& كروه & \\
\hline & & $\cdot / 1 \wedge \vee$ & T/TFA & IT & درون كروهى & Menhinick \\
\hline & & & $\Delta / 9 \mid r$ & IV & كل & \\
\hline \multirow[t]{3}{*}{. $/$ Tr } & $1 / 9 \Delta \Delta$ & 1/9QH & N/TGK & $\Delta$ & بين 4 كروه & \\
\hline & &.$/ 991$ & $11 / 91$ & ir & درون كروهى & Margalef \\
\hline & & & $r \cdot / K F F$ & IV & كل & \\
\hline \multirow[t]{3}{*}{.$/ 1 \mathrm{Fr}$} & $r / \cdot \Delta r$ & $\cdot 1 \cdot 1$ & $.|\cdot| 4 \mid$ & $\Delta$ & بين 4 كروه & \\
\hline & & $\cdot / \cdot f$ & $\cdot \mid \cdot \varphi \wedge$ & IT & درون گروهى & Equitability_J \\
\hline & & & .1 .9 & IV & كل & \multirow{3}{*}{ Fisher } \\
\hline \multirow[t]{2}{*}{.1 .91} & r/A9V & ו & $1 \Lambda \cdot / 1 \Delta V$ & $\Delta$ & بين 4 كروه & \\
\hline & & IT/KTA & $\mid \& q / T \Delta \Lambda$ & ir & درون گروهى & \\
\hline
\end{tabular}




\begin{tabular}{|c|c|c|c|c|c|c|}
\hline & & & $r T q / 41 Q$ & IV & كل & \\
\hline \multirow[t]{3}{*}{ - 1994 } & $.19 \Delta \Delta$ & 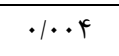 & $.1 \cdot r$ & $\Delta$ & بين 9 كروه & \\
\hline & & .1 .94 & $\cdot 1 \cdot V \Delta$ & IT & درون گروهى & Berger \\
\hline & & & .1 .90 & IV & كل & \\
\hline \multirow[t]{3}{*}{$\cdot r \cdot r$} & $1 / \pi 49$ & $\mid r T / T \cdot Y$ & $991 / 019$ & $\Delta$ & بين 9 كروه & \\
\hline & & $99 / 9 \vee 9$ & $119 \cdot 11 \cdot 1$ & IT & درون گروهى & Chao \\
\hline & & & IATIGTV & IV & كل & \\
\hline
\end{tabular}

"اختلاف معنى دار در سطح ه درصد.

*Different is significant at $\mathrm{P}<0.05$.

جدول س- مقايسه اختلاف معنى دارى تيمارهاى مختلف بين و درون بخشهاى مختلف سوخته و نسوخته براساس آزمون دانكن.

Table 3. Comparison of the significant differences between different treatments between and within different parts of burnt and unburnt areas based on Duncan's test.

\begin{tabular}{|c|c|c|c|}
\hline تعداد افراد & شاخص منهنيك & 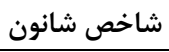 & 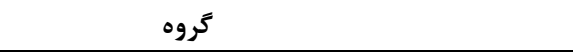 \\
\hline abri. & $a b r / v$ & $a b r / v$ & كروه I تاج يوشش بيش از Td درصد در مناطق نسوخته \\
\hline$a b \backslash \vee q$ & $\mathrm{br} / \mathrm{r}$ & $\mathrm{b} r / 9$ & كروه r تاج يوشش بيش از لم درصد در مناطق سوخته \\
\hline arri & $a b r / v$ & abr & 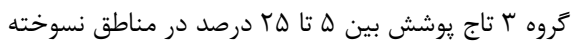 \\
\hline birr & $\mathrm{ar} / \mathrm{s}$ & $a r / l$ & گروه F تاج يوشش بين Q ل تا فD درصد در مناطق سوخته \\
\hline arte & $\mathrm{br} / \mathrm{c}$ & $a b r / v$ & كروه له تاج يوشش كمتر از له درصد در مناطق نسوخته \\
\hline b) 1 q & $\mathrm{ar} / \mathrm{s}$ & ar/l & كروه 9 تاج يوشش كمتر از ه درصد در مناطق سوخته \\
\hline
\end{tabular}

${ }^{a, b}$ The same letters do not differ significantly in each index.

درصد اختلاف معنى دار وجود ندارد. اما در مناطق نسوختهاى كه

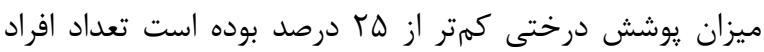

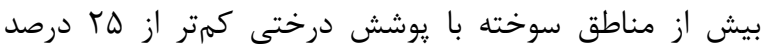
است. اين موضوع مىتواند بهدليل اثر آتشسوزى بر تراكم

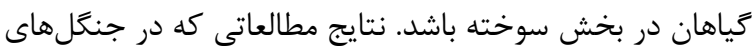

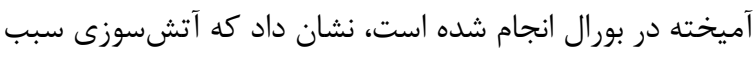
افزايش گونههاى علفى نوريسند شده است ( Metlen \& (Fiedler, 2005 از نظر غناى گونهاى، بر اساس نتايج مقايسات ميانگين دانكن، شاخص غناى مهينيك در بخش سوخته با يوشش درختى كمتر

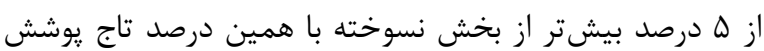

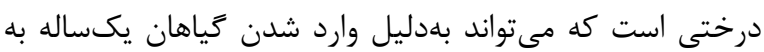

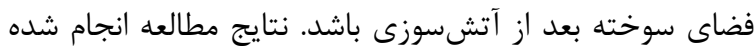

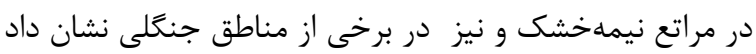

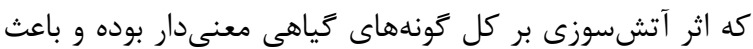

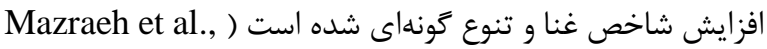
(2011; Ghorbani et al., 2011

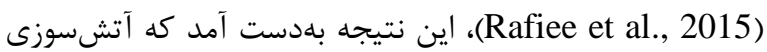
در بلندمدت باعث افزايش شاخصهاى تنوع، غنا و يكنواختى

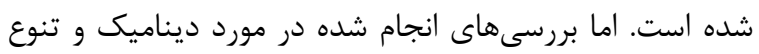

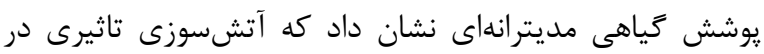
غناى گونهاى نداشته است (Capitanio \& Carcaillet, 2008).
Grime et al., ) بذرهاى ₹ياهى ضرورى تشخيص داده شداند 1981; Bond \& Keeley, 2005; Auld \& Denham, 2006; Galatowitsch, 2008 همجنين ضرورت و نقش آتش \& در احياى جنگل هاى سوزنى برى شمالى (تايگًا) به اثبات رسيده است (Kwiatkowska -Falinska et al., 2014)، ولى سئ آيا آتش همين نقش را نيز در رويشهاى ايران و در اين تحقيق، گونه سوزنى برى Juniperus excelsa دارد؟

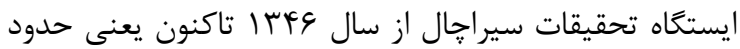

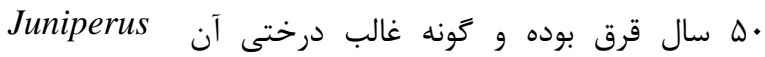
است. گونه excelsa ايران، وسيعترين يراكنش را داشته و از شمال، شمال غرب، شمال شرق تا جنوب ايران حضور دارد (Assadi, 1998). اين كونه اجتماعات مختلفى را در نواحى كوهستانى ناحيه رويشى سيى ايرانى-تورانى تشكيل داده و از نظر سينتاكسونوميكى از سطح رده، راسته، اتحاديه، جامعه و زيرجامعه در ساختار يوشش زياهى

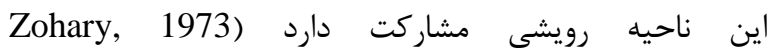
Ravanbakhsh et al., 2016; تحقيقات سيراجال اتفاق افتاده است منشاء انسانى داشته و عامل

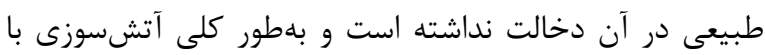
منشاء طبيعى در جنكَلهاى خشك ايران بهصورت نادر اتفاق مى افتد. نتايج ANOVA نشان داده است كه بين تعداد افراد در مناطق سوخته و نسوخته با ميزان يوشش درختى بالاى له 
Inula, آتشسوزى شده نيز به رشد خود ادامه داده داداند. همجنين Scariola orientalis در مراتع يزد نيز در برابر آتش مقاومت نشان داده است دمان Crepis sancta (Baghestani Meybodi et al., 2010) از گَونهاى يكسالهاى است كه فقط در بخش سوخته ديده شده است و احتمالا بعد از آتشسوزى به منطقه وارد شده است. Berberidaceae (Beris integerrima از درختجههايى است كه بعد از آتشسوزى زنده مانده و به حيات

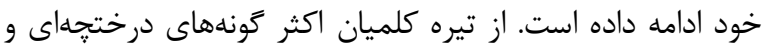
קندساله علفى بعد از آتشسوزى به حيات خود اده ادهامه دادهاند.

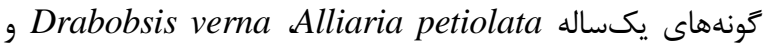
از گونههايى هستند كه بعد از آتشسوزى به منطقه وارد شدهاند. گونه Lonicera iberica از تيره آقطيان از زونههاى درختجهاى است كه در هر دو (Caprifoliaceae) منطقه سوخته و نسوخته حضور داشته است. همجنين تمام گونه هاى بوتهاى، جندساله علفى و يكساله تيره ميخكيان در منطقه سوخته حضور داشته و بعد از آتشسوزى زنده ماندهاند. از تيره خواجدباشيان دو گونه جندساله ثبت شده است كه هر دو گونه بعد از آتشسوزى زنده ماندهاند و تنها يك گونه يكساله، Scabiosa sp.

Geranium tuberosum از تيره شمعدانيان (Geraniaceae)، از گونههاى رايج در منطقه است كه با توجه به داشتن ريشه غدهاى بعد از آتشسوزى بهخوبى به حيات و رشد خود ادامه داده است. از تيره نعناعيان، اكثر گ گونهاى بخش نسوخته در بخش سوخته نيز

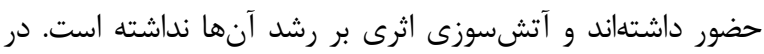
ساير مطالعات انجام شده نيز اين تيره بعد از آتشسوزى درصد

يوشش متوسطى را داشته است (Javadi \& Mamoon, 2011). تيره باقلائيان يكى از مهمترين تيرههايى است كه در مراتع ايران

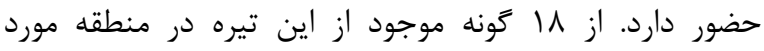

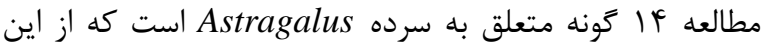
تعداد ^ گ گونه در هر دو بخش سوحته و نسوخته حضور داشته و نسبت به آتش مقاوم بودهاند. گونههاى جندساله علفى و بوتهاى A. A. chrysostachys Astragalus caspicus شامل (A. mesoleios , A. iranicus A. glumaceus ،citrinus از آتشسوزى از بين رفتهاند. در مراتع درودفرامان كرمانشاه،

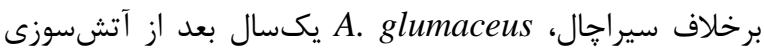

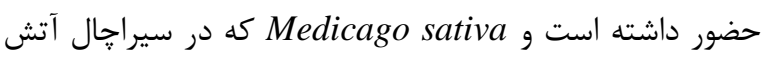
را تحمل كرده است در منطقه درودفرامان نيز از آتش در امان مانده است (Talai Tabar et al., 2017). از گ زونههاى بوتهاى

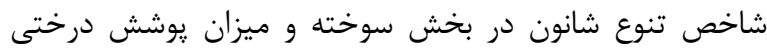

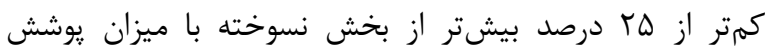

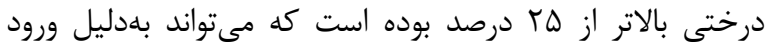
بعضى از گونههاى يكساله به منطقه بعد از آتشسوزى بارئ باشد. اين

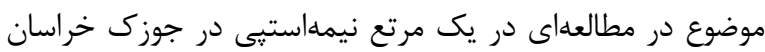

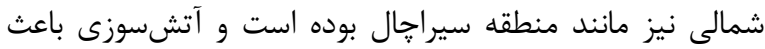
افزايش تنوع بهدليل حضور گونههاى يكساله شده است ( Rafiee كt al., 2015 Sanghoon et al., ) كوهاى گَوموسان مشاهده شده است

همجنين نتايج نشان مىدهند كه تفاوتهايى از نظر حضور آرايهها در دو بخش سوخته و نسوخته در رويشگاههاى مختلف وجود دارد. از آنجا كه مطالعه بخش سوخته سيراجال با هدف

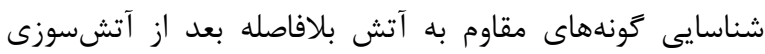

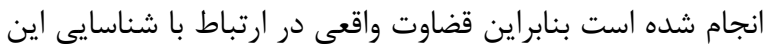
كونهها و روند رو به جلو يا عقب رَرد اكوسيستم نيازمند مطالعه يوشش گیاهى بعد از حداقل دو سال است. نتايج كنونى نشان

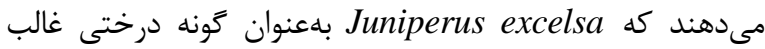
كاملا سوخته و بين بخشهاى نسوخته و سوخته با تاج يوشش كمتر از ها درصد اختلاف معنى دار از نظر تعداد افراد ساير گونهها

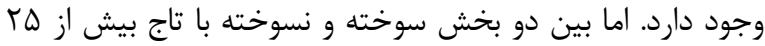

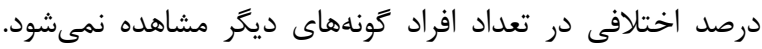

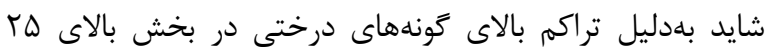

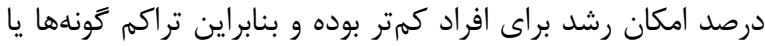

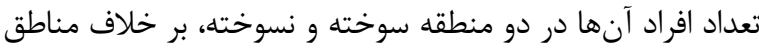

$$
\text { با يوشش درختى كمتر از له درصد، تفاوتى نداشته است. }
$$

در تيره كرفسيان به استثناء Chaerophyllum macropodum كه فقط در بخش نسوخته حضور دارد، تمام سردههاى گياهى بخش دئ برد نسوخته در بخش سوخته نيز حضور دارند و ظاهرا آتشسوزى تاثير

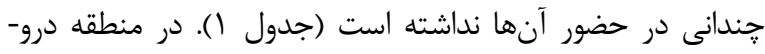
فرامان كرمانشاه نيز Ferula ovina از اولين گونههايى است كه إنها بعد از آتشسوزى سبز شده است. هر دو گونه اين سرده در سيراجال نيز بعد از آتشسوزى حضور داشتهاند (Talai Tabar et al., 2017). كونه Vincetoxicum funebre (Asclepiadiaceae)، كونهاى نادر در سيراجال است كه توانسته است بعد از آتشسوزى به بقاى خود ادامه دهد. تيره كاسنيان يكى از غنىترين تيرههاى كياهى منطقه در دو بخش سوخته و نسوخته است. سردههاى اين تيره در هر دو بخش سوخته و نسوخته حضور داشته و آتش تاثير جندانى بر

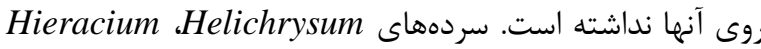




$$
\begin{aligned}
& \text { سياسگزارى } \\
& \text { نغارندكان از دكتر على اصغر معصومى، دكتر مصطفى اسدى و } \\
& \text { دكتر زيبا جمزاد جهت شناسايى برخى از نمونهایى كَاهى و نيز }
\end{aligned}
$$

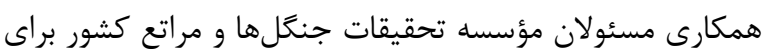

$$
\begin{aligned}
& \text { فراهم نمودن امكانات انجام اين تحقيق سياسگزارى مىنمايند. }
\end{aligned}
$$

\section{REFERENCES}

Akbarzadeh, M. 1994. Preparation of vegetation map of Sirachal region by floristic and physiognomic methods. RIFR, Tehran, $71 \mathrm{pp}$.

Assadi, M. (ed.) 1988-2018. Flora of Iran, vols. 1-148. RIFR. Tehran.

Assadi, M. 1998. Pinaceae, Taxaceae, Cupressaceae and Ephedraceae. In Assadi, M. et al. (eds.), Flora of Iran, vols. 19-22. RIFR, Tehran, pp. 21-27.

Auld, T.D. \& Denham, A.J. 2006. How much seed remains in the soil after a fire? Plant Ecol. 187: 15-24.

Baghestani Maybodi, N., Farahpour, M. \& Zare, M.T. 2010. Effect of fire on vegetation cover of steppe rangelands (a case study in Yazd province, Iran). Environ. Sci. 7: 37-42.

Bailey, A.W. 1988. Understanding fire ecology for range management. In Tueller, P.T. (ed.), Vegetation science applications for rangeland analysis and management; handbook of vegetation science, vol. 14. Springer, Dordrecht, pp. 527-557.

Barnes, B.V., Zak, D.R., Denton, S.R. \& Spurr, S.H. 1998. Forest ecology, ${ }^{4}$ th edition. John Wiley and Sons, USA, 774 pp.

Barnes, T.A. \& Van Lear, D.H. 1998. Prescribed fire effects on advanced regeneration in mixed hardwood stands. S. J. Appl. Forest. 22: 138-142.

Bond, W.J. \& Keeley, J.E. 2005. Fire as a global 'herbivore': the ecology and evolution of flammable ecosystems. Trends Ecol. Evol. 20: 387-394.

Brooks, M., Ostoja, S. \& Klinger, R. 2013. Fire effects on seed banks and vegetation in the eastern Mojave desert: Implications for post-fire management. JFSP research project reports, $81 \mathrm{pp}$. http:// digitalcommons. unl.edu/jfspresearch/81.

Capitanio, R. \& Carcaillet, C. 2008. Post-fire Mediterranean vegetation dynamics and diversity: A discussion of succession models. Forest Ecol. Managem. 255: 431-439.

Fattahi, B. \& Tahmasebi, A. 2010. Fire influence on vegetation changes of Zagros mountainous rangelands (Case study: Hamadan province). J. Rangeland 4: 228-239.

Ghorbani, J., Safaeian, N. \& Tamartash, R. 2011. Vegetation changes after the fire in semi-arid rangelands. International Fire Conference on Natural resources, Gorgan, $7 \mathrm{pp}$.

Galatowitsch S. 2008. Seedling establishment in restored ecosystems. In Leck., M.A., Parker, T., Simpson, R. (eds.), Seedling Ecology and Evolution, Cambridge University Press, Cambridge, pp. 352-372.

Grime J.P., Mason G., Curtis A.V., Rodman J., Band S.R., Mowforth M.A.G., Neal A.M. \& Shaw S.
خاردار منطقه Astragalus compactus تا حدودى بعد از آتشسوزى به حيات خود ادامه داده است اما festucaceum از تيره كلاه ميرحسنيان (Plumbaginaceae)

$$
\text { در آتش سوخته است. }
$$

كونهاى درختجهاى منطقه اكثرا متعلق به تيره گلسرخيان

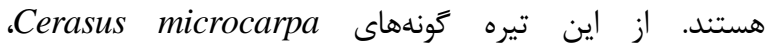
Rosa , C. nummularia ،Cotoneaster nummularioides

canina

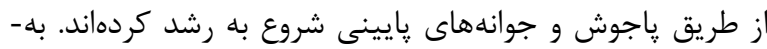

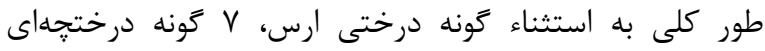

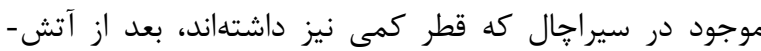

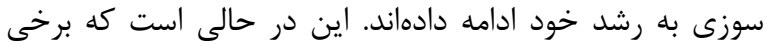

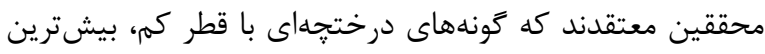
Guevara et al., 1999; ) سيب را بعد از آتشسوزى ديدهانين (Talai Tabar et al., 2017 زاگرس (Moradi et al., 2016) كونه Cerasus microcarpa) بعد از آتشسوزى به حيات خود ادامه داده است. همجنين در مطالعات انجام شده در جنكلهاى يهنبرك اينسوبريخ، كَونه -

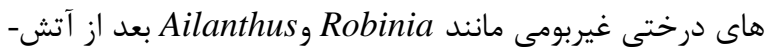

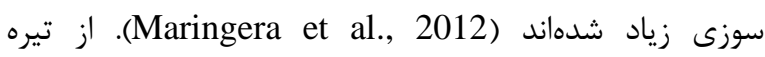
روناسيان، تونههاى جندساله سرده Galium نسبت به آتش

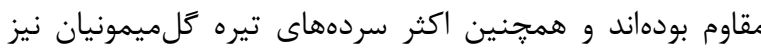
بعد از آتشسوزى به حيات خود ادامه دادهاند. از كياهان تكليهاى، گونههاى تيره سوسنيان بهدليل داشتن

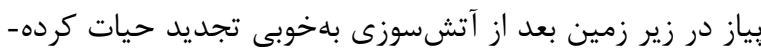

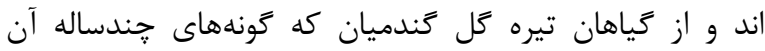
تيڤهاى غالب را در منطقه مورد مطالعه تشكيل مى مدهند، همكى نسبت به آتش مقاوم بوده و فقط دو كونه متعلق به سرده آدراي

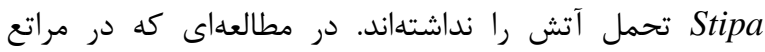

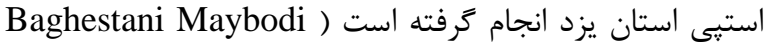

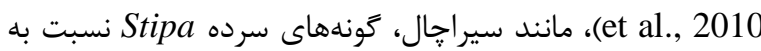

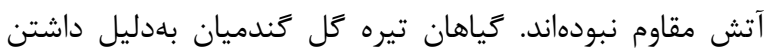

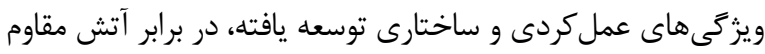

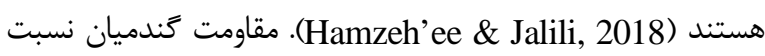

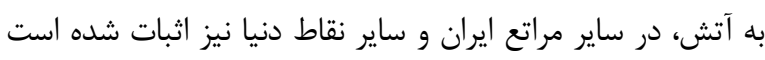
Ortmann et al., 2008; Javadi, \& Mamoon, 2011; Talai ) (Tabar et al., 2017; فقط كونه Bromus tectorum نسبت به آتش مقاومت نداشته

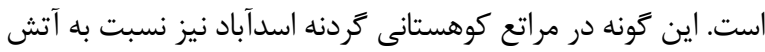
غيرمقاوم بوده است (Fattahi \& Tahmasebi, 2010). 
1981. A comparative study of germination characteristics in a local flora. J. Ecol. 69: 1017-1059.

Guevara, J.C., Stasi, C.R., Wuilloud, C.F. \& Estevez, O.R. 1999. Effects of fire on rangeland vegetation in southwestern Mendoza plains (Argentina): composition, frequency, biomass, productivity and carrying capacity. J. Arid Environm. 41: 27-35.

Hammer, Ø. 1999-2018. Manual of Past version 3.19. Natural History Museum, University of Oslo, $158 \mathrm{pp}$.

Hamzehee, B. 2019. Investigation of fire effects on soil seed bank and vegetation in Sirachal Research Station (Final report), Research Institute of Forests and Rangelands, $80 \mathrm{pp}$.

Hamzeh'ee, B. \& Jalili, A. 2018. The importance of Poaceae in nature and human life. JIN 2: 46-55.

Jamshidi Bakhtar, A., Marvie Mohadjer, R.M., SaghebTalebi, K. Namiranian, M. \& Maroufi, H. 2014. Alternation of plant diversity after fire in Zagros forest stands, case study: Marivan forests. IJFPR 21: 529-541.

Javadi, S.A. \& Mamoon, Z. 2011. Natural burning effects on some vegetation and soil characteristics of rangeland (Case study: Pir Gol Sorkh Behbahan Rangeland). JNRR 2: 45-54.

Kalkhan, M.A., Stafford, E. \& Stohlgren, T. 2007. Rapid plant diversity assessment using a pixel nested plot design: A case study in Beaver meadows, Rocky Mountain National Park, Colorado, USA. Divers. Distrib. 13: 379-388.

Keeley, J.E. \& Keeley, S.C. 1981. Post-fire regeneration of southern California chaparral. Amer. J. Bot. 68: 524-530.

Khalilpoor, M., Jalilvand, H., pourmajidian, M. \& Hojati, S.M. 2013. Investigation of the effect of fire on vegetation diversity of Zagros forests (Case study: Dale protected area in Kohgiluyeh and Boyerahmad province). First National Conference on Environmental Research of Iran, Hamadan, 23 pp. https://www.civilica.com/Paper-NCER01NCER01_405.html.

Koutsias, N. \& Karteris, M. 2000. Burned areas mapping using logistic regression modeling of a single post-fire Landsat-5 Thematic Mapper image. Int. J. Remote Sensing 21: 673-687.

Kwiatkowska-Falińska, A., Jankowska-Błaszczuk, M. \& Jaroszewicz, B. 2014. Post-fire changes of soil seed banks in the early successional stage of pine forest. Pol. J. Ecol. 62: 455-466.

Maringera, J., Wohlgemuth, T., Nef, C., Pezzatti, G.B. \& Conedera, M. 2012. Post-fire spread of alien plant species in a mixed broad-leaved forest of the Insubric region. Flora 207: 19-29.

Metlen, K. L. \& Fiedler, C. E. 2005. Restoration treatment effects on the under story of ponderosa Pine/Douglas- fire forest in Western Montana, USA. Forest Ecol. Managem. 222: 355-369.

Moradi, B., Ravanbakhsh, H., Moshki, A. \& Shabanian, N. 2016. The effect of fire on vegetation structure in Zagros forests (case study: Sarvabad, Kurdistan province). IJF 8: 381-392.

Mazraeh, M., Habashi, H., Kavousi, M. \& Shafiei, A. 2011. Comparison of biodiversity of forest vegetation after fire. International Fire Fighting Conference on Natural Resources, Gorgan, 8 pp.

Moreira, F., Delgado, A., Ferreira, S., Borralho, R., Oliveira, N., Inacio, M., Silva, J.S. \& Rego, F. 2003. Effects of prescribed fire on vegetation structure and breeding bird in young Pinus pinaster stands of northern Portugal. Forest Ecol. Managem. 184: 225-237.

Ortmann, J., Beran, D.D., Masters, R.A. \& Stubbendieck, J.L. 2008. Grassland management with prescribed Fire. Nebraska cooperative extension. EC 98-148. Historical materials from university of Nebrasca-Lincoln Extension. http://digitalcommons.unl.edu/extensionhist/1296.

Rafiee, F., Ejtahadi, H. \& Jankju, M. 2015. Study of plant diversity at different time intervals after burning in a semiarid rangeland. JPR (IJB) 27: 854-864.

Ravanbakhsh, H., Hamzeh'ee, B., Etemad, V., Marvie Mohadjer, M.R. \& Assadi, M. 2016. Phytosociology of Juniperus excelsa M.Bieb. forests in Alborz mountain range in the north of Iran. Pl. Biosyst. 150: 987-1000.

Rechinger, K.H. (ed.). 1963-2015. Flora Iranica, vols. 1-174. Akademische Druck- u. Verlagsanstalt, Graz; vol. 175. Akademische Verlagsgesellschaft, Salzburg; vols. 176181. Naturhistorisches Museum, Wien.

Sanghoon, C., Woen, K. \& Che, S. 1997. Comparison of plant community structures in cut and uncut areas at burned area of Mt. Gumo-San. J. Kor. Forestry Soc. 86: 509-520.

Shahlai, A., Javadi, S.A., Saedi, K. \& Afaridegan, A. 2012. The intentional fire effects on the vegetation of rangelands around Sanandaj (case study of Abidar Mountain and Hasan Abad area). ${ }^{3}$ rd Conference on Rangeland, Watershed and Desert, Karaj. 5 pp. https://www.civilica.com/Paper-RWD03RWD03_143.html.

Shokri, M., Safayian, N., \& Atrakchali, A. 2001. Fire effect on Golestan park vegetation. JNE (IJNR). 55: 273-281.

Talai Tabar, S.M., Tataeian, M.R. \& Tamartash, R. 2017. The short-term effect of fire on vegetation structure and soil physico-chemical properties in non-wooded rangelands of Dorood Faraman. JRM 3: 1-18.

Zohary, M. 1973. Geobotanical fundations of the Middle East. vols. 1-2. Fischer Verlag, Stuttgart, Amesterdam, $738 \mathrm{pp}$.

How to cite this article:

Hamzeh'ee, B., Khoshnevis, M., Ashouri, P., Mozaffarian, V. \& Ravanbakhsh, H. 2020. The effect of fire on vegetation diversity indices, a case study: Sirachal research station. Nova Biologica Reperta 7: 92-105. (In Persian).

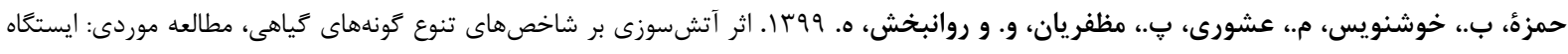

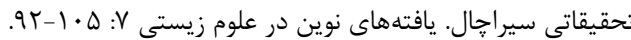

